Research Article

\title{
Investigation of Aerodynamic Stability of a Lightweight Dual-Arm Power Transmission Line Inspection Robot under the Influence of Wind
}

\author{
Ahmad Bala Alhassan $\left(\mathbb{D},{ }^{1}\right.$ Xiaodong Zhang, ${ }^{1,2}$ Haiming Shen, ${ }^{1}$ Guo Jian, ${ }^{1}$ Haibo Xu, ${ }^{1,2}$ \\ and Khaled Hamza ${ }^{1}$ \\ ${ }^{1}$ School of Mechanical Engineering, Xi'an Jiaotong University, Xi'an 710049, China \\ ${ }^{2}$ Shaanxi Province Key Laboratory of Intelligent Robotics, Xi'an Jiaotong University, Xi'an 710049, China \\ Correspondence should be addressed to Ahmad Bala Alhassan; amadkabo@stu.xjtu.edu.cn
}

Received 30 July 2019; Revised 17 September 2019; Accepted 3 October 2019; Published 6 November 2019

Academic Editor: Luis Payá

Copyright (C) 2019 Ahmad Bala Alhassan et al. This is an open access article distributed under the Creative Commons Attribution License, which permits unrestricted use, distribution, and reproduction in any medium, provided the original work is properly cited.

\begin{abstract}
To efficiently transmit electric power to consumers, the power lines need to be inspected routinely for early fault detection. Thus, power line inspection robots are designed to replace the tedious and dangerous manual inspection using linemen or helicopters. However, most of the existing inspection robots are heavy, which make them slow and prone to external wind disturbance. This paper developed a lightweight dual-arm robot and investigates its robustness to wind disturbance on a lab-scale power line structure. The dynamic equations of the robot are derived using the Lagrangian equation for appropriate motor selection. Also, the components of the robot are designed to ensure low drag coefficient to wind flow, and the mechanism of the wind force on the robot-line coupled system is presented. To study the real-time impact of the wind, a wind speed of $4.5 \mathrm{~m} / \mathrm{s}$ representing one of the windiest cities in China is considered as a case study. The experimental results for different wind directions, namely, $0^{\circ}, 45^{\circ}$, and $90^{\circ}$, show that the maximum vibration is $8 \%$ higher than the normal vibration of the system in a controlled environment without wind. The results demonstrate that there is little influence of the wind on the system; hence, the robot has been successfully designed and can be applied for power line inspection.
\end{abstract}

\section{Introduction}

For a reliable transmission of electric power, the power transmission lines (PTLs) need regular inspections for early fault detection and maintenance. Recognition and localization of faults along the PTL equipment are essential as it helps the power transmission companies minimize maintenance cost and prevents unwanted power outages $[1,2]$.

Traditionally, trained linemen climb and crawl along the PTL to detect faults or perform maintenance task. This line crawling technique is the most common inspection method and still-in-use in most of the world. However, the lives of the linemen could be in danger as they may fall from the line or even electrocuted [3, 4]. Another method involves the use of telescopes to inspect the lines from the ground. Although the ground foot patrol assured the safety of the human inspector, it is sluggish and highly inefficient since it may not provide the clear visualization of the line $[5,6]$. In addition, those manual inspection methods would be difficult to be employed when the PTLs cut-across mountains, water bodies, hot deserts, and thick forests.

Interestingly, power transmission line inspection robots (PTLIRs) are designed to autonomously inspect the condition of the PTLs safely with less cost as compared to the aforementioned manual methods. Sawada et al. [7] of Tokyo Electric Power Co., Japan, were reported to be one of the earliest researchers to design and develop a practical mobile PTLIR in 1991. Over these three decades, the field of PTL inspection has become a research interest of many scholars and research institutes around the world. In general, the 
PTLIRs can be classified into three broad categories, namely, the climbing, flying, and hybrid robots. The climbing PTLIRs typically have two or more arms that climb and roll along the line for the PTL inspection. As surveyed in [8-10], climbing robots are stable and provide more reliable inspection data due to their proximity to the line.

Hydro-Quebec research institute, Canada, is one of the leading institutes that designed a practical tele-operated climbing PTLIR known as the LineScout in [11, 12]. The $120 \mathrm{~kg}$ heavy structure has been extensively tested on a $735 \mathrm{kV}$ line. Another advanced climbing robot is the Expliner, developed by Hibot Co., Japan, in [13, 14]. The $30 \mathrm{~kg}$ Expliner is less heavier than the LineScout, and it is deployed to the PTL using an access cable. Expliner has a maximum inspection speed of $40 \mathrm{~m} / \mathrm{min}$ and can roll along a $500 \mathrm{kV}$ line at an inclination of $30^{\circ}$. However, the stability of Expliner is not guaranteed due to its complex maneuvers during automation. Other types of climbing PTLIRs include the line-walking mechanism $[15,16]$, three-arm prototype [17, 18], four-arm POLIBOT [19], five-arm structure $[20,21]$, and snake-like mechanism $[22,23]$, among others. However, most of the existing climbing PTLIRs are either heavy or relatively large and can easily be affected by external wind. This not only makes obstacle avoidance difficult but also makes loading the robots onto the line tasking and challenging.

On the contrary, the flying PTLIRs use the unmanned aerial helicopters (UAHs) [24-28] or the smart quadrotors [29-32] to inspect the PTLs. Consequently, these robots provide an alternative in terms of the faster inspection process and the convenient bypass of obstacles as compared to the climbing PTLIRs $[33,34]$. However, flying robots are highly vulnerable to external wind disturbance, and their natural vibratory motion can make the inspection data blurred. In addition, flying robots require high-definition cameras as the robots are relatively far from the lines, and unlike the climbing robots, an advanced line following algorithm is needed for the autonomous inspection of the line [35].

Thirdly, the recently introduced hybrid PTLIRs combined the climbing and the flying capabilities in a single structure as presented in [36-38]. The additional flying ability is utilized to carry the platform to the line and/or while bypassing obstacles, whereas the climbing mechanism moves the complete robot along the line for the inspection process. Nonetheless, hybrid PTLIR requires a complex control strategy to cater for its stability issues particularly under the influence of wind.

Conversely, due to its low structural damping and high flexibility, the power line conductors are sensitive to the external natural phenomenon (e.g., wind, ice, and rain). The effect of those factors leads to cable fractures, tower breakdown, and or damage to other PTL components [39-41]. Thus, it is crucial to study the impact of the induced vibration on the line and the PTLIR for effective automation of the robots.

Zhou et al. [42-44] are some of the works that modeled the mechanism of rain-wind induced vibration of power line conductors using finite element analysis. The authors investigate the effect of different parameters, namely, wind speed, damping ratio, and frequency, on the stability of the conductors. In addition, the dynamic analysis of a coupled tower-line system under the influence of wind and rain loads has been investigated in [45]. The study demonstrated that the effect of both wind and rain loads could significantly induce vibration on the tower-line system and thus, should not be ignored while designing the power line system.

Also, Fu et al. $[46,47]$ perform a fragility assessment of collapse status for a power line tower under wind-rain loads. The result identifies the unfavorable combinations of wind loads that lead to tower collapse. Other tower-line wind studies include stability analysis of strong wind in coastal areas [48, 49], nonlinear inelastic analysis under turbulent winds [50], wind tunnel test on aero-elastic model [51], and full-scale numerical simulations of failure mechanism under extreme winds [52, 53], among others. However, those studies only studied the effect of wind, rain, or ice on the PTL system without incorporating other equipment like the PTLIRs.

In addition to their large surface area which is prone to wind devastation, the existing robots also failed to consider wind effect to their design for stability assessments. In [54], only the speed and direction of the wind acting on the robot was measured as part of the environmental sensing unit. Some other works mentioned the wind effect on the PTLIRs as a potential future research. The main objective of this work is to improve the existing robots in terms of complexity, size, weight, and vulnerability to wind attack. Thus, we have developed a portable, lightweight dual-arm robot less prone to wind attack during PTL inspections. The study considered the effect of wind disturbance on the robot by carefully selecting its parts (arms and trunk) with less wind drag. The 3D dynamic equation of the robot-line coupled system was derived using the Lagrangian equations, and its response was analyzed using MATLAB. Finally, the system was tested on a laboratory PTL setup using an industrial fan as the wind source.

The paper is divided into five parts. The second part presents the description and the joint dynamics of the robot. The third part highlights the mechanism of wind disturbance on a robot-line system. The experimental setup of the robot-line and its response are presented in part four. Finally, the summary and conclusion are given in section five.

\section{Description and Dynamics of the Robot}

2.1. Mechanical Design. The PTLIR designed for this study is a dual-arm climbing robot that moves along a single PTL conductor, as shown in the conceptual design of Figure 1. The robot consists of two triangular grippers, two cylindrical arms, and a rectangular base that housed the onboard battery and other electronic components. Each gripper has three rollers; one connected to a motor for rolling along the line while the remaining two provide additional support to the arm. Thus, the complete robot has eight motors: two motors (ROL-M1\&2) for the active rollers, two motors (ADJ-M1\&2) for adjusting the grippers for proper alignment 


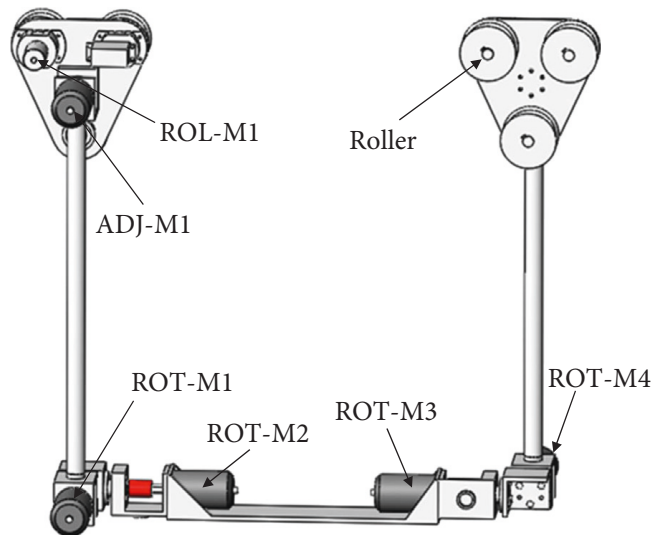

Figure 1: The structural design of the proposed robot. The complete robot has eight motors: two motors (ROL-M1\&2) for the active rollers, two motors (ADJ-M1\&2) for adjusting the grippers for proper alignment on the line, and four motors (ROT-M1-4) for manipulating the arms during the obstacle avoidance process.

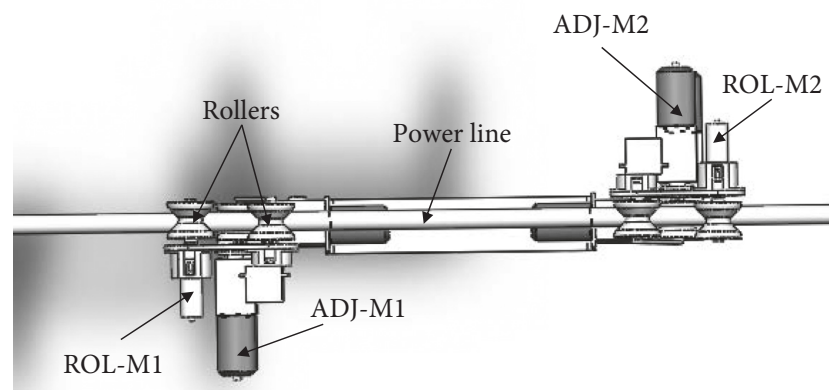

FIgURE 2: The plan view of the proposed robot that illustrates the arrangement of the rollers along a power line.

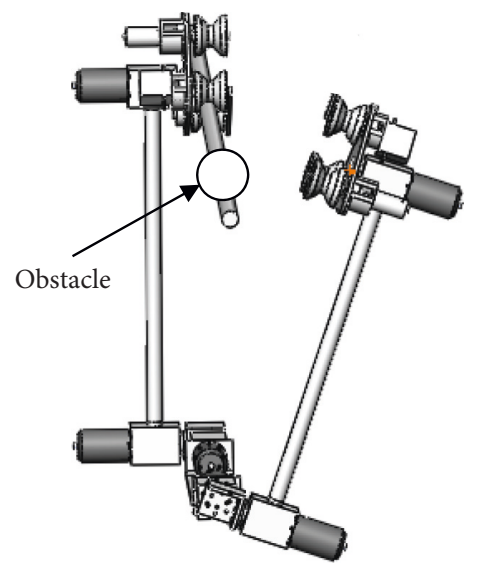

FIgURE 3: The process of bypassing an aircraft warning ball along the line. One arm is lifted and rotated away from the line in order to avoid the obstacle.

on the line, and four motors (ROT-M1-4) for manipulating the arms during the obstacle avoidance process.

Figure 2 shows the plan view of the design that clearly illustrates the arrangement of the rollers on the line. Also, the function of the adjustment motors is illustrated in Figure 3, where one arm is lifted and rotated away from the line in order to avoid an obstacle (circular warning ball). As shown, once an obstacle is detected, the robot stops while the front motors ROT-M1\&2 lift the front arm off the line and the ADJ-M1 then rotates the arm away from the line. The rear-arm then moves the robot towards the obstacle to allow the front arm to bypass the obstacles. Then, the front arm will be reattached to the line using ADJ-M1 and ROTM1\&2. At this point, the obstacle is between the two arms; the same process is repeated for the rear-arm ROT-M3\&4 and ADJ-M2 to finally avoid the obstacle. The individual 
TABle 1: Design parameters of the robot.

\begin{tabular}{lcccc}
\hline S/N & Length $(\mathrm{mm})$ & Width $(\mathrm{mm})$ & Thickness $(\mathrm{mm})$ & Mass $(\mathrm{kg})$ \\
\hline Gripper & 177 & 150 & 3 & 1.20 \\
Cylindrical arm & 400 & 20 & 3 & 0.80 \\
Trunk & 450 & 60 & 3 & 2.20 \\
\hline
\end{tabular}

masses and dimensions of each component are presented in Table 1.

2.2. Joint Torque Dynamics. In order to select appropriate motors for the operations of the robot, the torque analysis should be conducted. In this case, we consider the scenario where the maximum torque will be required to lift or rotate each joint while one arm is fixed on the line, as shown in Figure 4(a). Thus, the structure of the two arms was proposed to be identical such that any of the arms can be lifted or manipulated. Although the robot has six joints, two motors shared the same joint at joint 2 (ROTM1 \& ROT-M2) and joint 3 (ROT-M3\&ROT-M4). The pairs ROT-M2\&3 and ROT-M1\&4 have the same function and require the same magnitude of torque since similar manipulations will be required when the robot moves in the other direction. This means that to manipulate any arm, only the sequential motors (ROL-M1, ROT-M1, and ROT-M3) or (ROL-M2, ROT-M4, and ROT-M2) will be automated. Also, the magnitudes of the joint torques depend on the mass and length of the links which remain the same whether the motor rotates in or out of phase. Thus, the robot can be simplified to four joints and modeled in a single plane for the dynamic analysis.

By assuming the masses of each link to be concentrated at the tip of the links, the Lagrangian approach is employed to the simplified schematics of Figure $4(\mathrm{~b})$ to derive the dynamic equations of the system, where $m_{1}, m_{2}, m_{3}$, and $m_{4}$ are the masses of the hanging roller, link 1, link 2 , and link 3 , respectively. $\tau_{1}, \tau_{2}$, and $\tau_{3}$ are the torques required to lift link 1 , link 2, and link 3, respectively. Also, $l_{1}$ and $\varphi_{1}, l_{2}$ and $\varphi_{2}$, and $l_{3}$ and $\varphi_{3}$ represent the lengths and joint angles of their respective links.

Furthermore, the required linear force $f_{\mathrm{r}}$ capable of moving the whole robot a distance $\gamma$ along the power line can be determined. The general Lagrangian formulation of equation (1) given in [55] was used for deriving the joint equations of the robot, where $m_{i}$ is the mass of $i$ th coordinates, $Q_{i}$ is the summation of the $i$ th nonconservative forces, and $q_{i}$ is the $i$ th generalized independent point for $n$ number of coordinates. $T$ and $U$ denote the total kinetic and potential energies of the system, respectively. $h_{i}$ is the vertical height from the center of the $i$ th joint to the reference point, O.

The vertical height of each coordinate is expressed in equation (3); hence, the total energies $T$ and $U$ of equation (2) can be calculated, as shown in equations (4) and (5), respectively. Then, the dynamics of the robot can be calculated by solving equation (1) using equations (4) and (5) as expressed in equation (6) to equation (9):

$$
\begin{gathered}
\frac{\mathrm{d}}{\mathrm{d} t}\left(\frac{\mathrm{d} T}{\mathrm{~d} \dot{q}_{i}}\right)-\frac{\mathrm{d} T}{\mathrm{~d} q_{i}}+\frac{\mathrm{d} U}{\mathrm{~d} q_{i}}=Q_{i} ; \quad i=1,2,3, \ldots, n, \\
T=\sum_{i=1}^{n} \frac{1}{2} m_{i} \dot{q}_{i}^{2} ; \\
U=\sum_{i=1}^{n}\left(m_{i} g h_{i}\right), \\
h_{1}=-l_{1} \cos \varphi_{1} ; \\
h_{2}=-\left(l_{1} \cos \varphi_{1}+l_{2} \cos \varphi_{2}\right) ; \\
h_{3}=-\left(l_{1} \cos \varphi_{1}+l_{2} \cos \varphi_{2}+l_{3} \cos \varphi_{3}\right), \\
T=\frac{1}{2}\left(m_{1234} \dot{\gamma}^{2}+m_{234} l_{1}^{2} \dot{\varphi}_{1}^{2}+m_{34} l_{2}^{2} \dot{\varphi}_{2}^{2}+m_{4} l_{3}^{2} \dot{\varphi}_{3}^{2}\right) \\
+m_{234} \dot{\gamma}_{1} \dot{\varphi}_{1} \cos \varphi_{1}+m_{34} \dot{\gamma} l_{2} \dot{\varphi}_{2} \cos \varphi_{2}+m_{4} \dot{\gamma} l_{3} \dot{\varphi}_{3} \cos \varphi_{3} \\
+m_{34} l_{1} l_{2} \dot{\varphi}_{1} \dot{\varphi}_{2} \cos \left(\varphi_{1}-\varphi_{2}\right)+m_{4} l_{1} l_{3} \dot{\varphi}_{1} \dot{\varphi}_{3} \cos \left(\varphi_{1}-\varphi_{3}\right) \\
+m_{4} l_{2} l_{3} \dot{\varphi}_{2} \dot{\varphi}_{3} \cos \left(\varphi_{2}-\varphi_{3}\right),
\end{gathered}
$$

$U=-m_{234} g l_{1} \cos \varphi_{1}-m_{34} g l_{2} \cos \varphi_{2}-m_{4} g l_{3} \cos \varphi_{3}$,

$f_{\mathrm{r}}=m_{1234} \ddot{\gamma}+m_{234} l_{1} \ddot{\varphi}_{1} \cos \varphi_{1}+m_{34} l_{2} \ddot{\varphi}_{2} \cos \varphi_{2}$

$+m_{4} l_{3} \ddot{\varphi}_{3} \cos \varphi_{3}-m_{234} l_{1} \dot{\varphi}_{1}^{2} \sin \varphi_{1}-m_{34} l_{2} \dot{\varphi}_{2}^{2} \sin \varphi_{2}$

$-m_{4} l_{3} \dot{\varphi}_{3}^{2} \sin \varphi_{3}$,

$$
\begin{aligned}
\tau_{1}= & m_{234} l_{1}^{2} \ddot{\varphi}_{1}+m_{234} \ddot{\gamma} l_{1} \cos \varphi_{1}+m_{34} l_{2} l_{1} \ddot{\varphi}_{2} \cos \left(\varphi_{1}-\varphi_{2}\right) \\
& +m_{4} l_{1} l_{3} \ddot{\varphi}_{3} \cos \left(\varphi_{1}-\varphi_{3}\right)+m_{34} l_{1} l_{2} \dot{\varphi}_{2}^{2} \sin \left(\varphi_{1}-\varphi_{2}\right) \\
& +m_{4} l_{1} l_{3} \dot{\varphi}_{3}^{2} \sin \left(\varphi_{1}-\varphi_{3}\right)+m_{234} g l_{1} \sin \varphi_{1},
\end{aligned}
$$

$$
\begin{aligned}
\tau_{2}= & m_{34} l_{2}^{2} \ddot{\varphi}_{2}+m_{34} \ddot{\gamma}_{2} \cos \varphi_{2}+m_{34} l_{1} l_{2} \ddot{\varphi}_{1} \cos \left(\varphi_{1}-\varphi_{2}\right) \\
& +m_{4} l_{2} l_{3} \ddot{\varphi}_{3} \cos \left(\varphi_{2}-\varphi_{3}\right)-m_{34} l_{1} l_{2} \dot{\varphi}_{1}^{2} \sin \left(\varphi_{1}-\varphi_{2}\right) \\
& +m_{4} l_{2} l_{3} \dot{\varphi}_{3}^{2} \sin \left(\varphi_{2}-\varphi_{3}\right)+m_{34} g l_{2} \sin \varphi_{2}, \\
\tau_{3}= & m_{4} l_{3}^{2} \ddot{\varphi}_{2}+m_{4} \ddot{\gamma} l_{3} \cos \varphi_{3}+m_{4} l_{1} l_{3} \ddot{\varphi}_{1} \cos \left(\varphi_{1}-\varphi_{3}\right) \\
& +m_{4} l_{2} l_{3} \ddot{\varphi}_{2} \cos \left(\varphi_{2}-\varphi_{3}\right)-m_{4} l_{1} l_{3} \dot{\varphi}_{1}^{2} \sin \left(\varphi_{1}-\varphi_{3}\right) \\
& -m_{4} l_{2} l_{3} \dot{\varphi}_{2}^{2} \sin \left(\varphi_{2}-\varphi_{3}\right)+m_{4} g l_{3} \sin \varphi_{3} .
\end{aligned}
$$

Finally, the dynamic equations can be expressed in the matrix form of equation (10) in equation (11), where the terms with double derivatives represent the acceleration of 


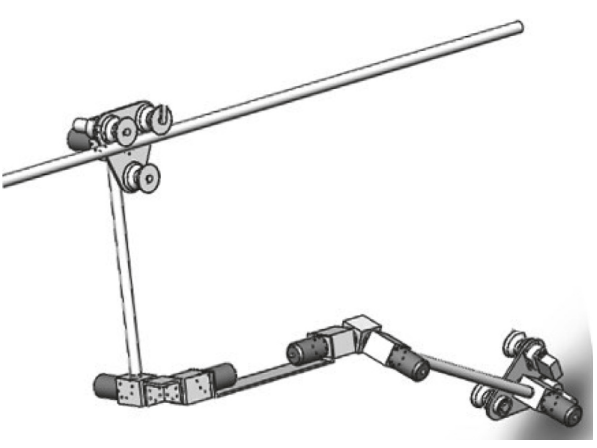

(a)

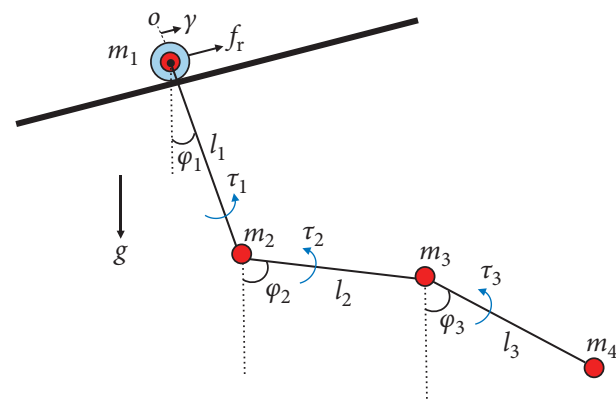

(b)

Figure 4: Representations of the proposed robot. (a) The structural design of the robot with one gripper on the line while manipulating its joints; (b) schematic diagram of the robot showing the parameters of each link for the dynamic modelling.

the links, terms with the single squared derivatives represent the centripetal acceleration of the links, and $g$ terms represent the gravitational accelerations. From the parameters of Table 1 , it can be deduced that $l_{1}=0.4 \mathrm{~m}, l_{2}=0.45 \mathrm{~m}$, $l_{3}=0.4 \mathrm{~m}, \quad m_{1}=1.2 \mathrm{~kg}, \quad m_{2}=0.8 \mathrm{~m}, \quad m_{3}=2.2 \mathrm{~kg}, \quad$ and $m_{4}=1.2 \mathrm{~kg}$. Thus, the torque analysis of each joint with respect to the joint angles can be conducted in MATLAB ${ }^{\circledR}$ software.

$$
\begin{aligned}
\tau= & m(\varphi, \ddot{\varphi})+B\left(\varphi, \dot{\varphi}^{2}\right)+G(\varphi), \\
{\left[\begin{array}{l}
f_{\mathrm{r}} \\
\tau_{1} \\
\tau_{2} \\
\tau_{3}
\end{array}\right]=} & {\left[\begin{array}{cccc}
m_{1234} & m_{234} l_{1} \cos \varphi_{1} & m_{34} l_{2} \cos \varphi_{2} & m_{4} l_{3} \cos \varphi_{3} \\
m_{234} l_{1} \cos \varphi_{1} & m_{234} l_{1}^{2} & m_{34} l_{1} l_{2} \cos \left(\varphi_{1}-\varphi_{2}\right) & m_{4} l_{1} l_{3} \cos \left(\varphi_{1}-\varphi_{3}\right) \\
m_{34} l_{2} \cos \varphi_{2} & m_{34} l_{1} l_{2} \cos \left(\varphi_{1}-\varphi_{2}\right) & m_{34} l_{2}^{2} & m_{4} l_{2} l_{3} \cos \left(\varphi_{2}-\varphi_{3}\right) \\
m_{4} l_{3} \cos \varphi_{3} & m_{4} l_{1} l_{2} \cos \left(\varphi_{1}-\varphi_{3}\right) & m_{4} l_{2} l_{3} \cos \left(\varphi_{2}-\varphi_{3}\right) & m_{4} l_{3}^{2}
\end{array}\right]\left[\begin{array}{c}
\ddot{\gamma} \\
\ddot{\varphi}_{1} \\
\ddot{\varphi}_{2} \\
\ddot{\varphi}_{3}
\end{array}\right] } \\
& +\left[\begin{array}{cccc}
0 & m_{234} l_{1} \sin \varphi_{1} & m_{34} l_{2} \sin \varphi_{2} & -m_{4} l_{3} \sin \varphi_{3} \\
0 & 0 & m_{34} l_{1} l_{2} \sin \left(\varphi_{1}-\varphi_{2}\right) & m_{4} l_{1} l_{3} \sin \left(\varphi_{1}-\varphi_{3}\right) \\
0 & -m_{34} l_{1} l_{2} \sin \left(\varphi_{1}-\varphi_{2}\right) & 0 & m_{4} l_{2} l_{3} \sin \left(\varphi_{2}-\varphi_{3}\right) \\
0 & -m_{4} l_{1} l_{3} \sin \left(\varphi_{1}-\varphi_{3}\right) & -m_{4} l_{2} l_{3} \sin \left(\varphi_{2}-\varphi_{3}\right) & 0
\end{array}\right]\left[\begin{array}{c}
\dot{\varphi}^{2} \\
\dot{\varphi}_{1}^{2} \\
\dot{\varphi}_{2}^{2} \\
\dot{\varphi}_{3}^{2}
\end{array}\right]+\left[\begin{array}{c}
0 \\
m_{234} g l_{1} \sin \varphi_{1} \\
m_{34} g l_{2} \sin \varphi_{2} \\
m_{4} g l_{3} \sin \varphi_{3}
\end{array}\right] .
\end{aligned}
$$

To simulate the responses, some assumption can be made for each joint variable, i.e., velocities and accelerations can be set to unity [19]. This means that the robot moves at a linear acceleration of $1 \mathrm{~m} / \mathrm{s}^{2}$ and angular acceleration of $1 \mathrm{rad} / \mathrm{s}^{2}$. Thus, to calculate the required torque for joint $1\left(\tau_{1}\right)$, joints 2 and 3 are fixed. Similarly, torques $\tau_{2}$ and $\tau_{3}$ can be calculated. By considering the normal sliding position of the robot, as shown in Figure 1, each joint is said to be at zero position (equilibrium). Thus, based on our analysis, it was observed that a manipulation within $30^{\circ}(0.53 \mathrm{rad})$ is enough to perform the intended obstacle avoidance process effectively. Thus, the limit of angular rotation for each joint is $-15^{\circ} \leq \varphi_{1} \leq 15^{\circ}$, $-20^{\circ} \leq \varphi_{2} \leq 20^{\circ}$, and $-30^{\circ} \leq \varphi_{3} \leq 30^{\circ}$ which corresponds to the maximum torques of $4.9 \mathrm{Nm}, 5.6 \mathrm{Nm}$, and $2.5 \mathrm{Nm}$, respectively, for joint 1 , joint 2 , and joint 3 , as shown in Figure 5.

For the analysis of the rolling force, $f_{\mathrm{r}}$, along the line, we can consider the case where the roller moves the whole robot while all the joints are inactive or fixed. Based on its dynamics of equation (6), a $5.0 \mathrm{Nm}$ torque is required to move the structure a distance of one meter, as shown in Figure 6. It is also clear that least force is needed to move the robot when all the joints rotate simultaneously.

\section{Mechanism of Wind Load on the Robot- Line System}

In this section, two models are presented. Initially, the generalized wind dynamics on the robot-line is presented. Then, the combined robot-line-wind dynamics and its simulation analysis are, respectively, presented.

3.1. Generalized Wind Force on the Robot-Line System. Figure 7 illustrates the potential wind disturbance on a robot-line couple system in one direction, $x$. The dynamics of the wind force $f_{\mathrm{w}}$ given in [45] can be represented in equation (12), where $C_{\mathrm{d}}$ is the drag coefficient, $A$ is the cross-sectional area, $\rho_{\mathrm{a}}$ is the air density, and $v_{\mathrm{a}}$ is the velocity of the wind. $C_{\mathrm{d}}$ is a dimensionless quantity used to quantify the resistance of an object in a flow environment (air or liquid), where small coefficient indicates less aerodynamic drag [56].

However, the wind attack angle $\theta$ on the robot-line system may not necessarily be perpendicular to the surface; hence, the schematics of the possible attack direction can be 


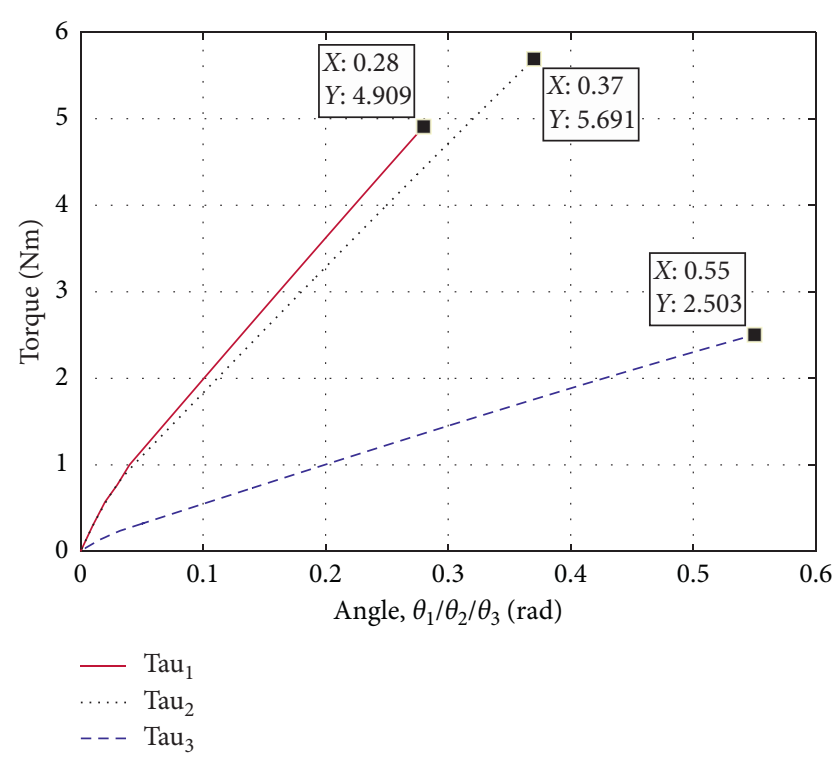

Figure 5: Torque response of links 1, 2, and 3 showing the maximum required torque to rotate each arm. It can be seen that the maximum joint rotation angles of $15^{\circ}, 20^{\circ}$, and $30^{\circ}$ correspond to the maximum torques of $4.9 \mathrm{Nm}, 5.6 \mathrm{Nm}$, and $2.5 \mathrm{Nm}$, respectively, for joint 1 , joint 2 , and joint 3 .

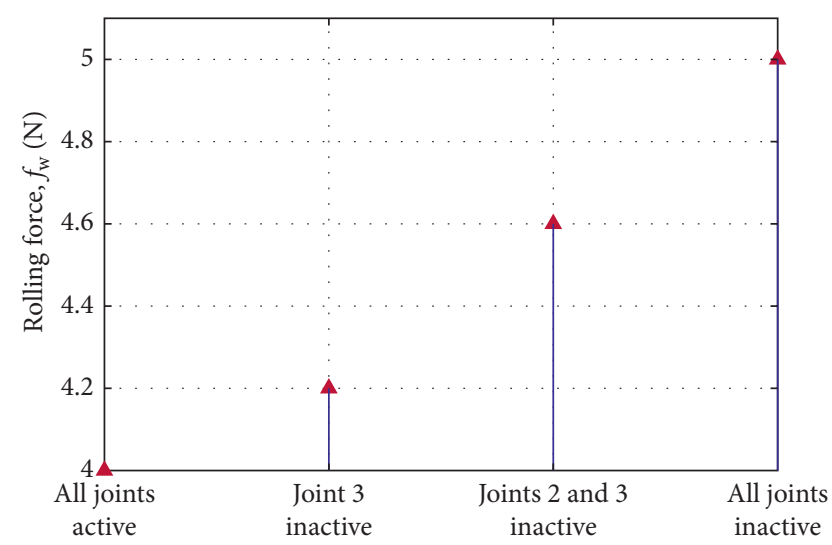

FIGURE 6: Response for the rolling force, $f_{\mathrm{r}}$, needed to move the robot along the line. When all the links are inactive, the highest torque of $5.0 \mathrm{Nm}$ is required to move the whole robot for a distance of one meter along the line. Thus, a lesser torque of $4.0 \mathrm{Nm}$ is needed to move the robot when all the joints rotate simultaneously.

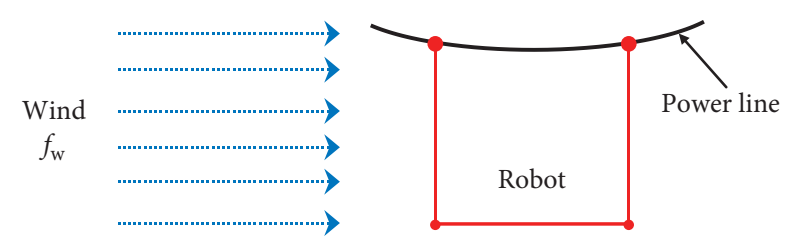

Figure 7: Potential wind disturbance on a robot-line coupled system.

represented using the plan view of Figure 7, as shown in Figure 8.

It can be seen that $\theta$ ranges from $0^{\circ}$ to $90^{\circ}$; hence, the general formulation of $f_{\mathrm{w}}$ can be modified as expressed in equation (13), where $C_{\mathrm{d} \_i x}$ and $A_{i x}$ denote the drag coefficient and cross-sectional area of the $i$ th components of the system in $x$ direction, respectively. $C_{\mathrm{d}_{-} i y}$ and $A_{i y}$ represent the drag coefficient and cross-sectional area of the $i$ th components in $y$ direction, respectively. Here, the number of components $n$ is six comprising two grippers, two arm pipes, a trunk, and the power line.

$f_{\mathrm{w}}=\frac{1}{2} \rho_{\mathrm{a}} v_{\mathrm{a}}^{2} C_{\mathrm{d}} A$,

$f_{\mathrm{w}}=\frac{1}{2} \rho_{\mathrm{a}} v_{\mathrm{a}}^{2} \sqrt{\left(\sum_{i}^{n} C_{\mathrm{d}_{\_} i x} A_{i x} \cos \theta\right)^{2}+\left(\sum_{i}^{n} C_{\mathrm{d}_{-} i y} A_{i y} \sin \theta\right)^{2}}$.

In reality, wind disturbance is a natural phenomenon, and thus, its effects on any object can be minimized by designing the system with an appropriate $C_{\mathrm{d}}$ and $A$. In summary, analyses of wind effect can be conducted by changing the wind speed $v_{\mathrm{a}}$ and or its attack angle $\theta$ as the two variables of equation (13).

3.2. Coupled Dynamics of Wind Load and the Robot-Line System. This section investigates the vibrations of the robot-line system under the influence of wind in $x, y$, and $z$ axes. Thus, the proposed robot under the influence of wind can be illustrated in Figure 9(a), where the dotted red lines represent the equilibrium position of the robot without wind effect. The two identical cylindrical arms are connected firmly by the robot trunk and driven along the PTL by the two identical rollers with linear force $f_{\mathrm{r}}$. Therefore, it is evident that the structure of the robot can be considered as coupled pendulum, where $l_{1}=l_{3}=l$. Thus, during wind attack, the position of the robot is illustrated in solid blue lines, and the corresponding angular displacements for the two arms can be assumed to be equal. So, the rotational motion of the arms due to the inertial moments $J$ given in equation (14) causes the angular displacements of the robot trunk in $x$-axis $(\psi)$ and $y$-axis $(\xi)$, respectively. Also, the vertical displacement of the robot in $z$-axis $(\delta)$ shown in Figure $9(\mathrm{~b})$ is expressed in equation (15).

$$
\begin{aligned}
& J=\frac{1}{2} m_{23} l^{2}, \\
& \delta=-l+l \cos \psi .
\end{aligned}
$$

In addition, $\gamma$ is the distance covered by the robot when it moves along the power line from the fixed reference point, $O\left(x_{o}, y_{o}\right.$, and $\left.z_{o}\right)$. As the main aim of this analysis is to study the vibration of the robot trunk, a single point on the trunk can be chosen. Thus, the position vector $p_{\mathrm{t}}$ of the robot trunk in a $3 \mathrm{D}$ plane with reference to the fixed coordinate system $O$ is given in equation (16). Then, the kinetic and potential energies of equation (2) can be calculated as expressed in equations (17) and (18), respectively. 


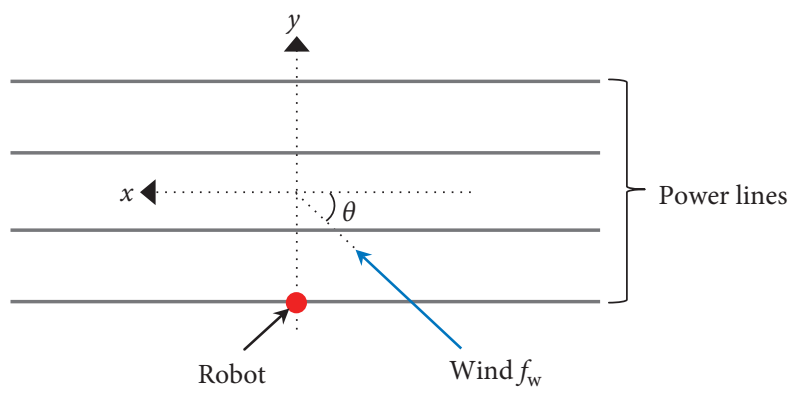

FIgURe 8: Possible wind attack direction for the robot-line coupled system.

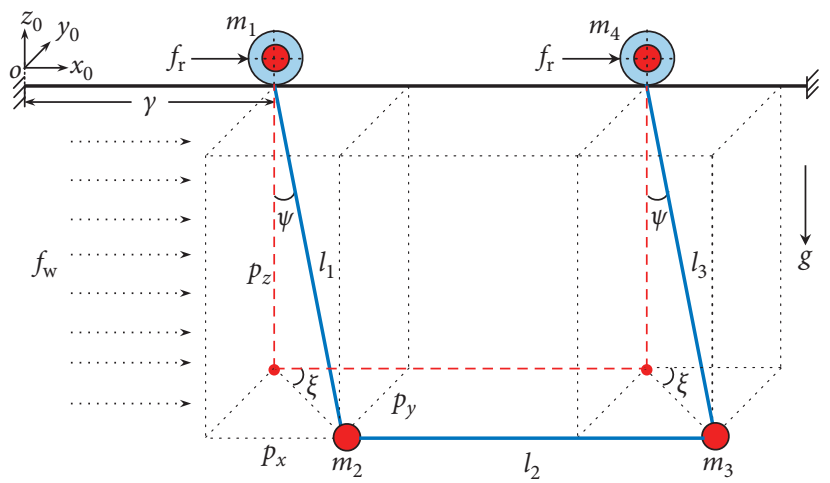

(a)

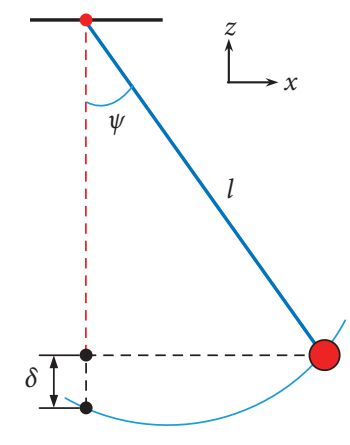

(b)

Figure 9: (a) The 3D schematics of the robot-line system under the influence of wind; (b) the 2D schematics of the robot showing its vertical displacement in $z$-axis.

$$
\begin{aligned}
p_{\mathrm{t}}= & \left\{\begin{array}{l}
(\gamma+l \sin \psi \cos \xi) i, \\
(l \sin \psi \sin \xi) j, \\
(-l \cos \psi) k,
\end{array}\right. \\
T= & \frac{1}{2} m_{1234} \dot{\gamma}^{2}+\frac{1}{2} m_{23}\left(\dot{\gamma}^{2}+l^{2} \dot{\psi}^{2}+l^{2} \dot{\xi}^{2} \sin ^{2}(\psi)\right. \\
& +2 l \dot{\gamma} \dot{\psi} \cos \psi \cos \xi-2 l \dot{\gamma} \dot{\xi} \sin \psi \sin \xi), \\
U= & -m_{23} g l \cos \psi .
\end{aligned}
$$

Moreover, the external forces $Q_{i}$ of the Lagrangian dynamics of equation (1) comprises the actuator force $f_{\mathrm{r}}$, the wind force $f_{\mathrm{w}}$, and the sinusoidal force $f_{\mathrm{s}}$ that cause the flexible line to oscillate along $y$-axis when the robot moves along the line. Thus, the complete dynamics of the robot under the influence of wind can be calculated by solving equation (1) using equations (17) and (18) as expressed in equation (19) to equation (21). It can be seen that the final dynamics of equations (20) and (21) are for the angular accelerations of the robot trunk. To determine the linear accelerations, the results should be multiplied by the radius of rotation, here, $l$.

$$
\begin{aligned}
& \ddot{\gamma}=\frac{1}{\left(m_{1234}\right)}\left(2 f_{\mathrm{r}}-m_{23} l \ddot{\psi} \cos \psi \cos \xi+m_{23} l \ddot{\xi} \sin \psi \sin \xi+m_{23} l \dot{\psi}^{2} \sin \psi \cos \xi+m_{23} l \dot{\xi}^{2} \sin \psi \cos \xi+2 m_{23} l \dot{\psi} \dot{\xi} \cos \psi \sin \xi\right), \\
& \ddot{\psi}=\frac{1}{\left(m_{23} l^{2}+J\right)}\left(-m_{23} l \ddot{\gamma} \cos \psi \cos \xi+m_{23} l^{2} \dot{\xi}^{2} \cos \psi \sin \psi-m_{23} g l \sin \psi+\frac{1}{2} \rho_{\mathrm{a}} v_{\mathrm{a}}^{2} \cos \theta \sum_{i}^{n} c_{\mathrm{d}_{-} i x} A_{i x}\right) \\
& \ddot{\xi}=\frac{1}{\left(m_{23} l^{2} \sin ^{2} \psi+J\right)}\left(f_{\mathrm{s}}+m_{23} l \ddot{\gamma} \sin \psi \sin \xi-2 m_{23} l^{2} \dot{\psi} \dot{\xi} \sin \psi \cos \xi+\frac{1}{2} \rho_{\mathrm{a}} v_{\mathrm{a}}^{2} \sin \theta \sum_{i}^{n} c_{\mathrm{d}_{-} i y} A_{i y}\right)
\end{aligned}
$$




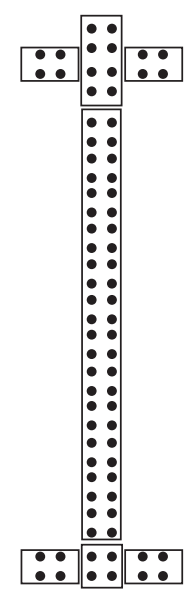

(a)

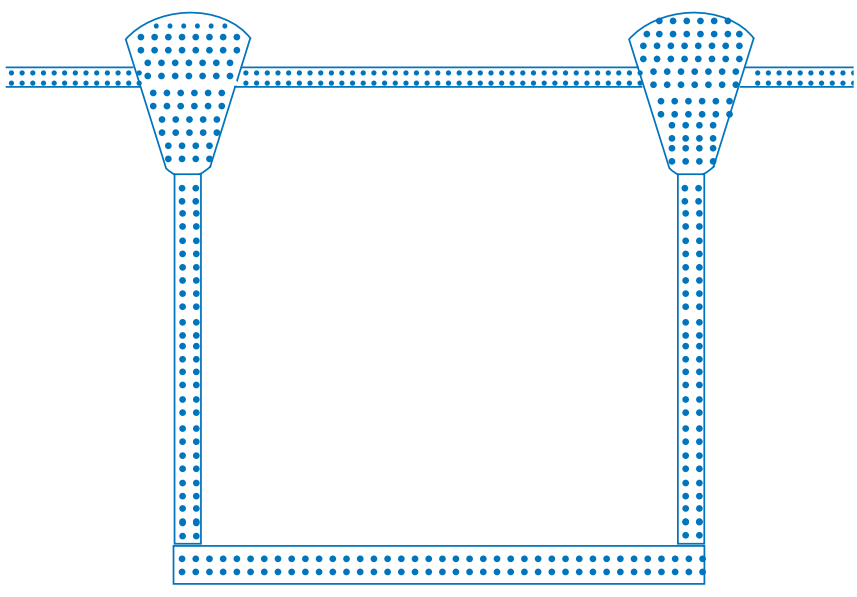

(b)

FIGURE 10: The total area affected by wind attack on the robot-line coupled system. (a) $x$-axis; (b) $y$-axis.

Finally, to analyze the dynamic equations, the areas affected by the wind attack should be calculated. Thus, the view of the wind attack in $x$ and $y$ axes of the robot-line system can be illustrated in Figure 10. The total area in each axis is calculated by summing the affected area of each item, as shown in Table 2. Thus, it is clear that the wind attacks larger surface area in $y$-axis as compared to the $x$-axis.

3.3. Simulation Analysis. To study the dynamic response of the system derived in equation (19) to equation (21), the robot was controlled at the speed of $10 \mathrm{~m} / \mathrm{min}$, and the flexibility of the line $f_{\mathrm{s}}$ was measured experimentally to have a maximum amplitude of $3 \mathrm{~cm}$ at $2 \mathrm{rad} / \mathrm{sec}$. In addition to this, the parameters of Table 2 were used for the simulations. Figure 11 shows the accelerations of the robot-line system under the influence of wind at $0^{\circ}, 45^{\circ}$, and $90^{\circ}$ in $x, y$, and $z$ axes, respectively. As shown, there is no significant peak in the range of frequencies of more than $3 \mathrm{~Hz}$, which shows the response is within the lower frequency spectrum.

As shown in Figure 11(a), the highest acceleration of $0.177 \mathrm{~m} / \mathrm{s}^{2}$ is obtained when the wind acts in the direction of motion of the robot $\left(0^{\circ}\right)$ as compared to $0.114 \mathrm{~m} / \mathrm{s}^{2}\left(45^{\circ}\right)$ and $0.126 \mathrm{~m} / \mathrm{s}^{2}\left(90^{\circ}\right)$. This shows that the vibration in the $x$-axis of the robot reduces when the wind blows perpendicular to the robot. Similarly, the response in $y$-axis (Figure 11(b)) shows that the highest vibration is obtained when the wind attacks the robot-line system at $90^{\circ}$. Also, the response demonstrates that significant vibrations are recorded at different frequencies, which translate higher wind effect on the system. On the contrary, the vibration recorded in the $z$-axis (Figure $11(\mathrm{c})$ ) is the least as compared to the $x$ and $y$ axes due to the absence of wind force in the $z$-axis.

To analyze the wind effect, the mean absolute values (MAE) of the responses are illustrated in Figure 11(d). As shown, the highest vibration of $0.483 \mathrm{~m} / \mathrm{s}^{2}$ in $x$-axis reduces to $0.423(12 \%)$ as the wind direction increases to $90^{\circ}$. However, the highest vibration in $y$-axis showed an increase in vibration from $0.415 \mathrm{~m} / \mathrm{s}^{2}$ to $0.539 \mathrm{~m} / \mathrm{s}^{2}$, representing a $30 \%$ increase as the wind attack increases from $0^{\circ}$ to $90^{\circ}$.

Moreover, the wind source is removed, and the ideal response of the robot-line system is recorded, i.e., moving, without wind. Then, the robot is stopped, and the wind attacks the system at $90^{\circ}$, i.e., stationary plus wind. These responses are compared with the highest vibration obtained when the robot moves under wind attack, as shown in Figure 12. The results show that wind has the least effect on the system when the robot is not moving in all cases. As shown in the summarized response of Figure 12(d), the highest vibration of the moving robot with the wind $\left(0.539 \mathrm{~m} / \mathrm{s}^{2}\right)$ shows a $17 \%$ increase in vibration as compared to the moving robot without wind $\left(0.462 \mathrm{~m} / \mathrm{s}^{2}\right)$. This shows little influence of the wind on the system.

\section{The Experimental Setup}

As the main objective of this work is to design an efficient PTLIR, an aluminum 6061 alloy was used to manufacture the robot. The $0.5 \mathrm{~m}$ by $0.5 \mathrm{~m}$ robot only weighs $7.5 \mathrm{~kg}$ including the electronic components; thus, it is much lighter and portable as compared with the existing PTLIRs as tabulated in [19]. All the motors were selected based on the torque analysis of equation (11), where the reliable Robomaster brushless DC motors are selected. In addition, all the motors were controlled using the C620 speed controllers provided by the manufacturer.

The experimental setup used for the verification of the effectiveness of the robot under different operating conditions is illustrated in Figure 13. As shown, the robot climbs along a $3 \mathrm{~m}$ long power transmission cable supported by two $1.8 \mathrm{~m}$ high vertical towers. Also, a cost-effective and lowpower ADXL335 tri-axis accelerometer was installed on the robot trunk for the measurement of the induced vibration of the coupled robot-power line system in all the three axes $(x$, $y$, and $z$ ). An industrial fan is chosen as the wind source for the aerodynamic analysis of the system, and the wind speed is determined using the AT816 digital anemometer. The wind generated by the fan attacked the system in three 
TABLE 2: Modelling parameters of the system.

\begin{tabular}{|c|c|c|}
\hline Parameter & Description & Value \\
\hline$l$ & Length of the arm & $0.177 \mathrm{~m}$ \\
\hline$m_{23}$ & Combined mass of arms and trunk & $3.8 \mathrm{~kg}$ \\
\hline$m_{1234}$ & Total mass of the robot & $6.2 \mathrm{~kg}$ \\
\hline$J$ & Moment of inertia & $0.03 \mathrm{kgm}^{2}$ \\
\hline$\rho_{\mathrm{a}}$ & Density of air & $1.225 \mathrm{~kg} / \mathrm{m}^{3}$ \\
\hline$v_{\mathrm{a}}$ & Velocity of air & $4.5 \mathrm{~m} / \mathrm{s}$ \\
\hline$A_{1 x}^{a}$ & Frontal area of the line in $x$-axis & $0.005 \mathrm{~m}^{2}$ \\
\hline$A_{1 y}$ & Frontal area of the line in $y$-axis & $0.12 \mathrm{~m}^{2}$ \\
\hline$C_{\mathrm{d} \_1 x}$ & Drag coefficient of the line in $x$-axis & 0.47 \\
\hline$C_{\mathrm{d} \_l y}$ & Drag coefficient of the line in $y$-axis & 0.42 \\
\hline$A_{2 x}$ & Frontal area of the roller in $x$-axis & $0.0104 \mathrm{~m}^{2}$ \\
\hline$A_{2 y}$ & Frontal area of the roller in $y$-axis & $0.0133 \mathrm{~m}^{2}$ \\
\hline$C_{\mathrm{d} \_2 x}$ & Drag coefficient of the roller in $x$-axis & 1.17 \\
\hline$C_{\mathrm{d} \_2 y}$ & Drag coefficient of the roller in $y$-axis & 0.38 \\
\hline$A_{3 x} / A_{3 y}$ & Frontal area of the arm in $x$ - or $y$-axis & $0.008 \mathrm{~m}^{2}$ \\
\hline$C_{\mathrm{d} \_3 x} / C_{\mathrm{d} \_3 y}$ & Drag coefficient of the arm in $x$ - or $y$-axis & 0.47 \\
\hline$A_{4 x}$ & Frontal area of the trunk in $x$-axis & $0.0134 \mathrm{~m}^{2}$ \\
\hline$A_{4 y}$ & Frontal area of the trunk in $y$-axis & $0.027 \mathrm{~m}^{2}$ \\
\hline$C_{\mathrm{d} \_4 x} / C_{\mathrm{d} \_4 y}$ & Drag coefficient of the trunk in $x$ - or $y$-axis & 0.82 \\
\hline
\end{tabular}
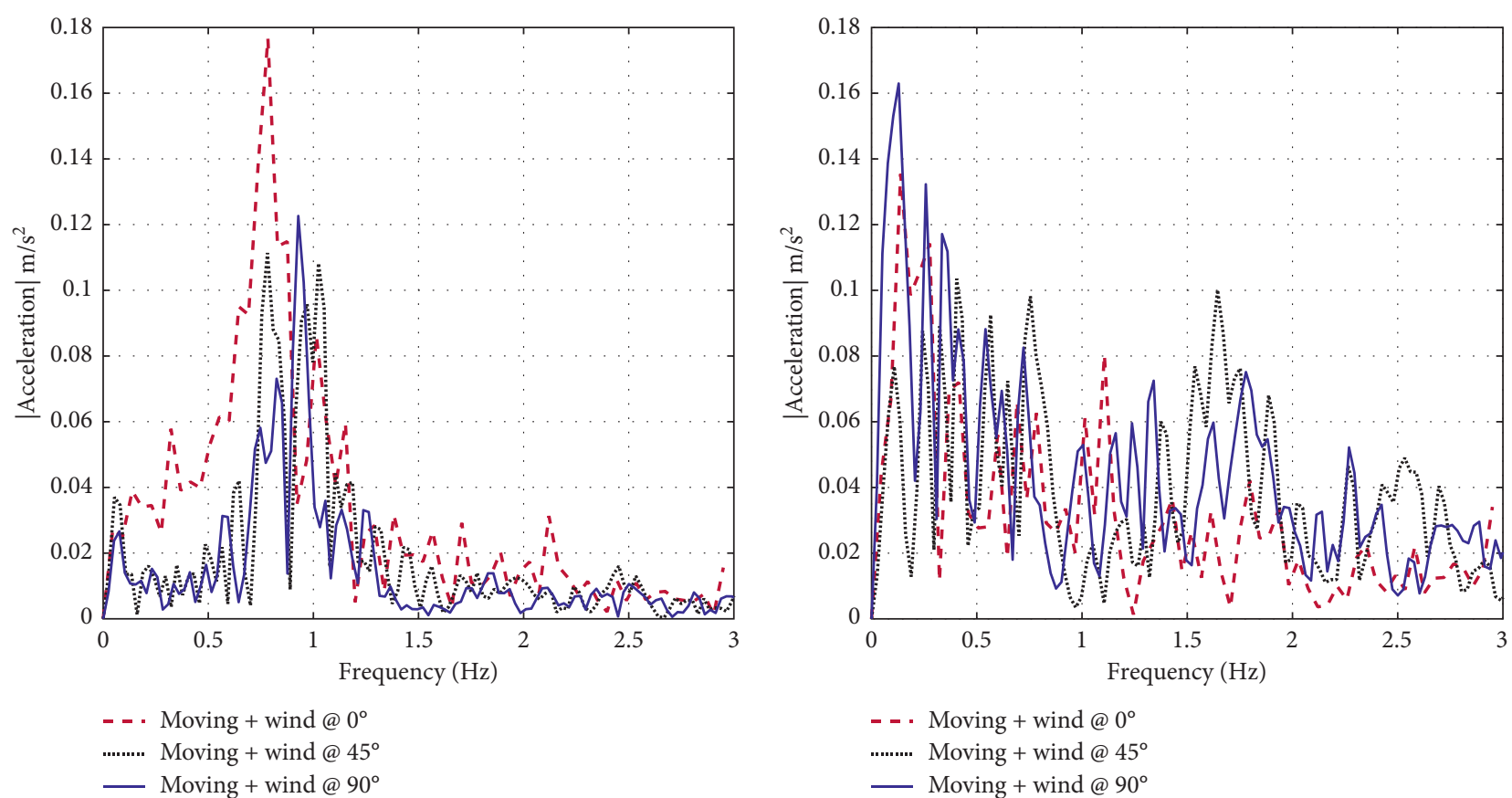

(a)

(b)

FIgure 11: Continued. 


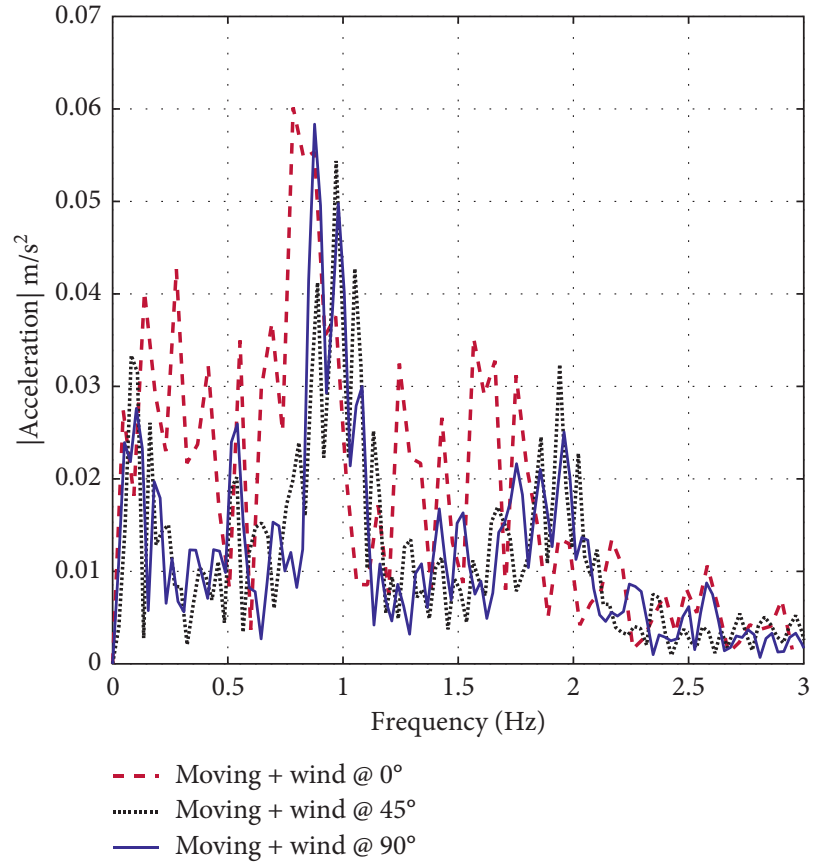

(c)

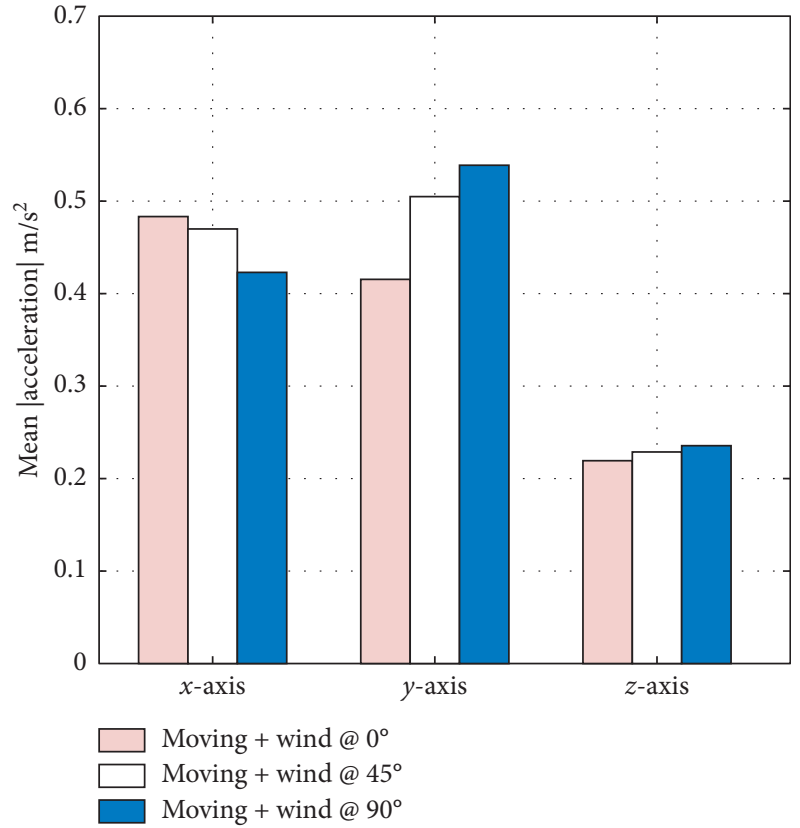

(d)

FiguRE 11: Simulation response of the moving robot under different wind attack angles. (a) $x$-axis; (b) $y$-axis; (c) $z$-axis; (d) summary.

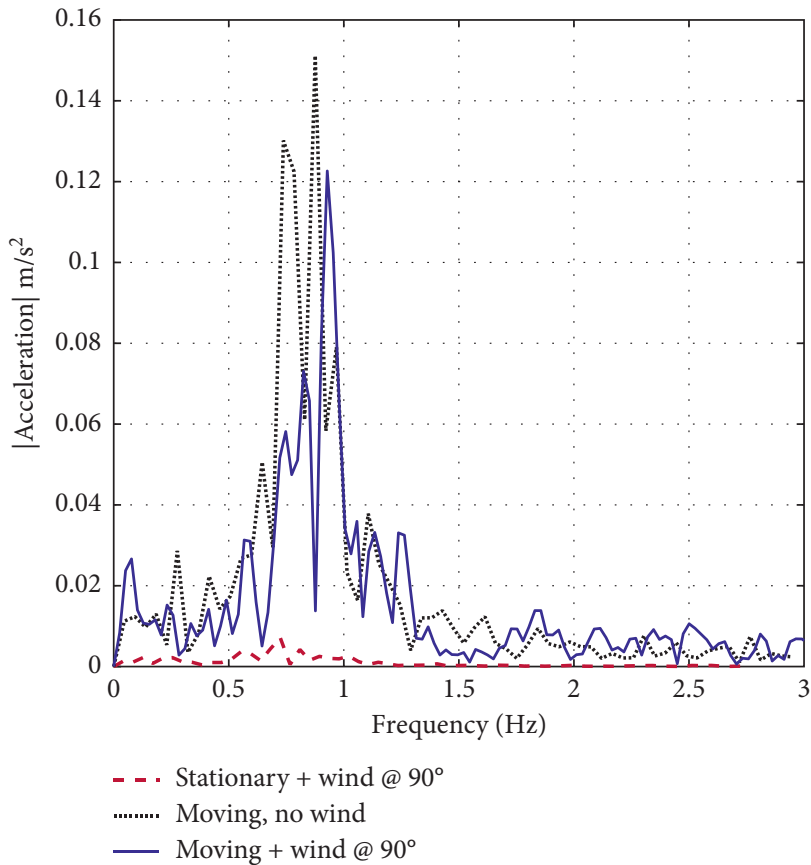

(a)

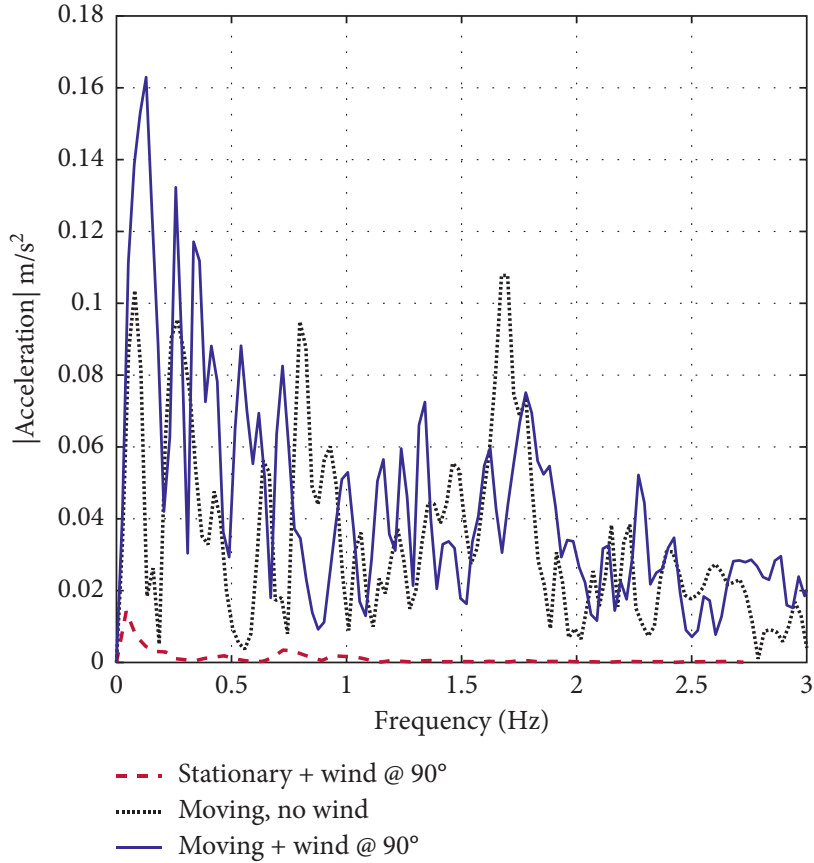

(b)

Figure 12: Continued. 


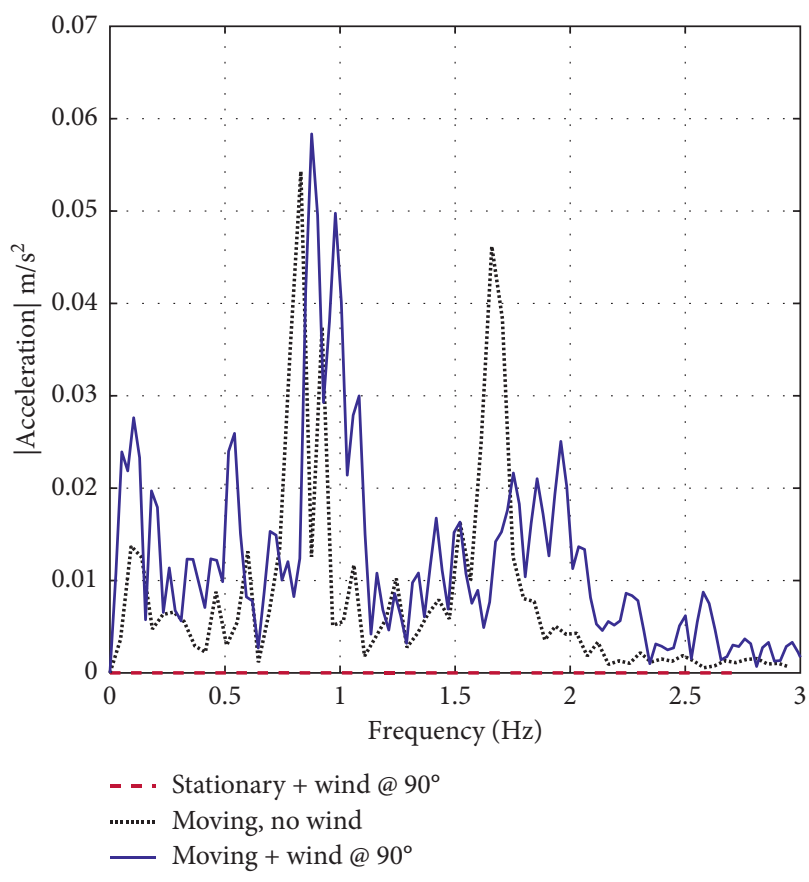

(c)

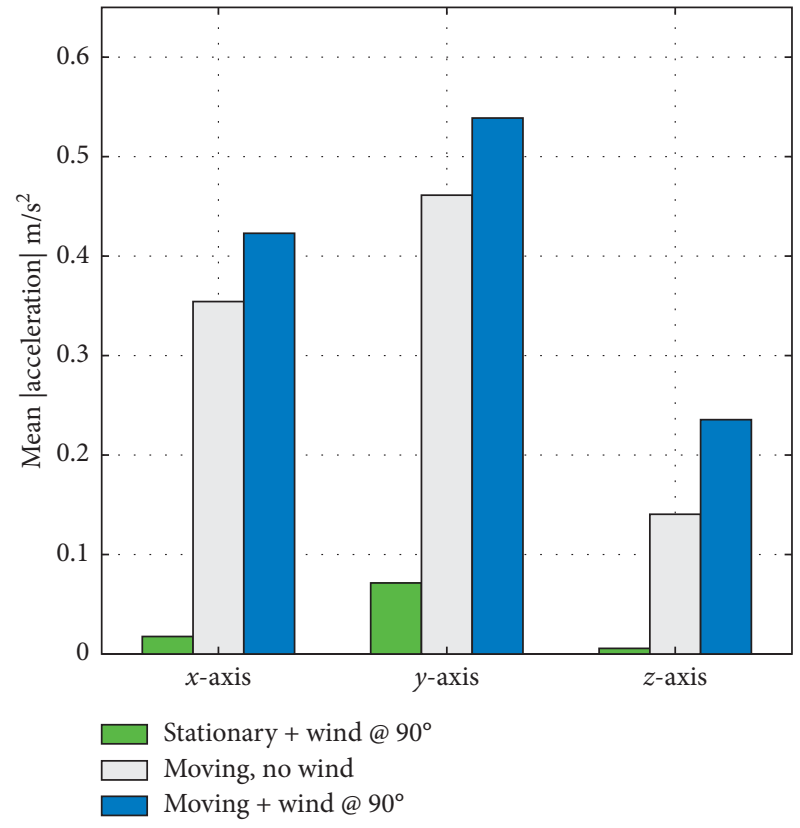

(d)

FIgURE 12: Simulation comparisons for the robot under different conditions. (a) $x$-axis; (b) $y$-axis; (c) $z$-axis; (d) summary.

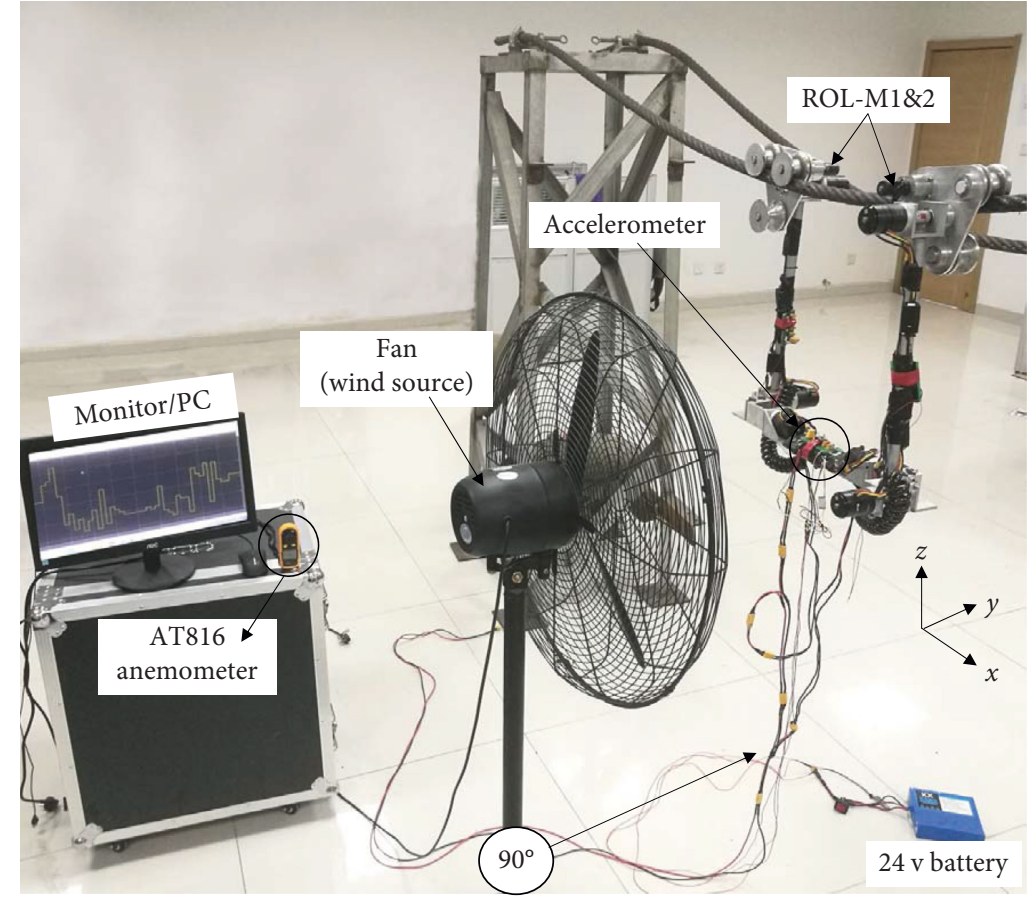

(a)

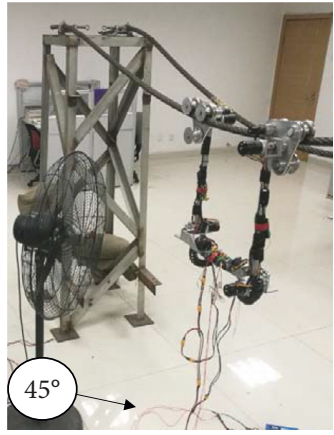

(b)

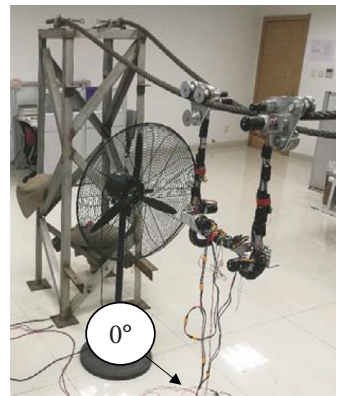

(c)

FiguRE 13: The experimental setup. (a) The complete arrangement of the system showing the inspection robot on a single conductor line under the influence of wind for a $90^{\circ}$ wind attack angle; (b) position of the fan at $45^{\circ}$ wind attack angle; (c) position of the fan at $0^{\circ}$ wind attack angle.

positions, namely, $0^{\circ}, 45^{\circ}$, and $90^{\circ}$. Finally, the Arduino Uno microcontroller connected to MATLAB ${ }^{\circledR}$ software serves as the data acquisition system for recording the vibratory response of the robot as displayed on the monitor/PC.

\section{Experimental Results and Analysis}

The analysis of the developed robot was conducted to verify its efficiency and robustness to external disturbance using 


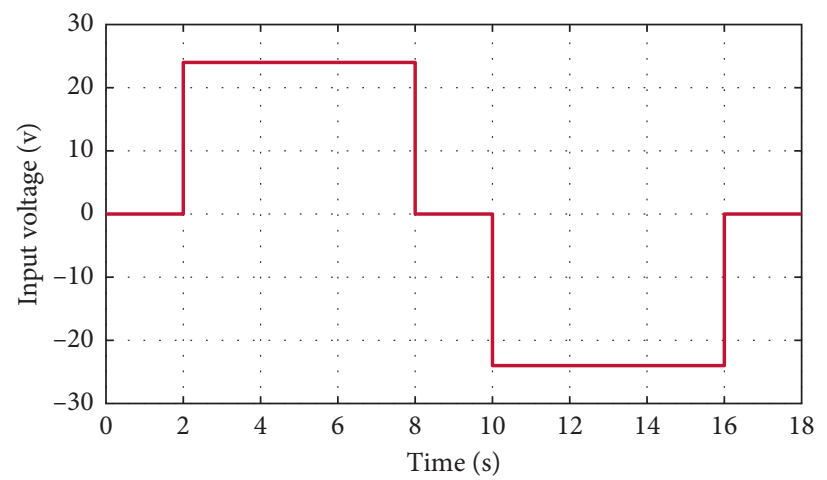

Figure 14: The controlled input signal for the operation of the robot. The robot moves forward along the line for 6 seconds and reverses for another 6 seconds. The robot is delayed for 2 seconds for each switching state for better operation of the robot.
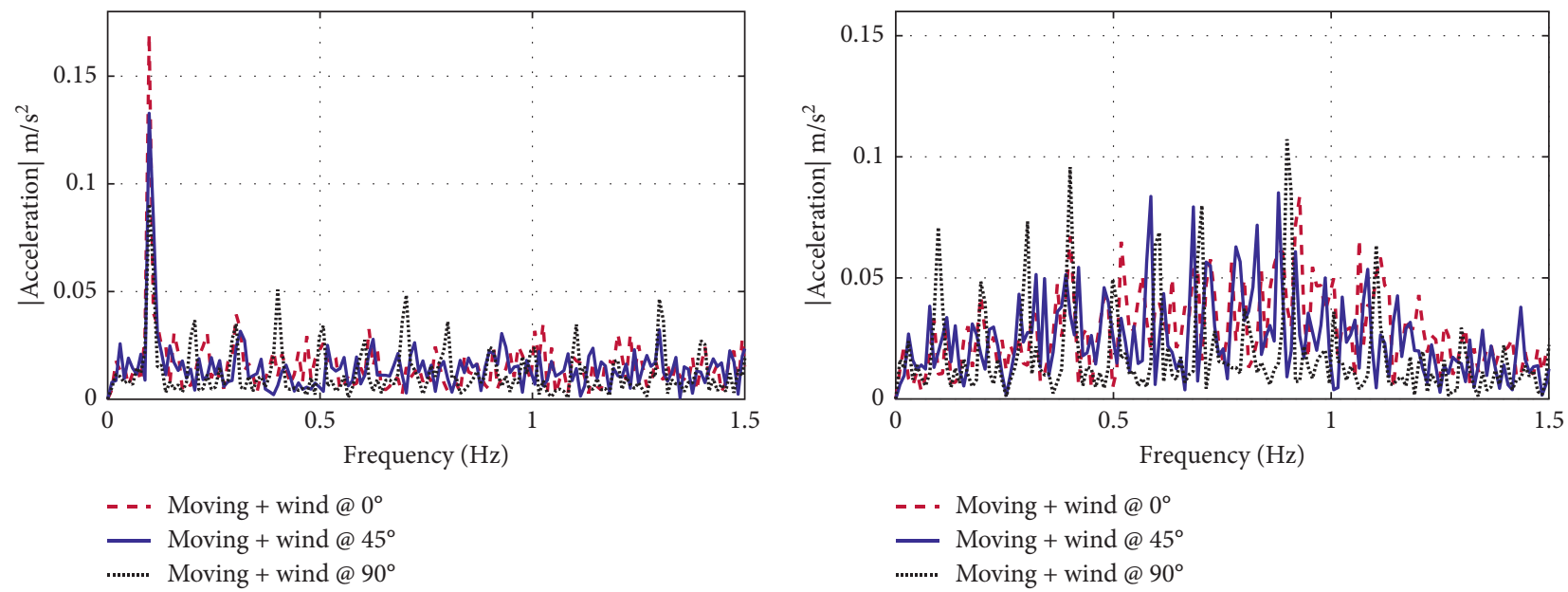

(a)

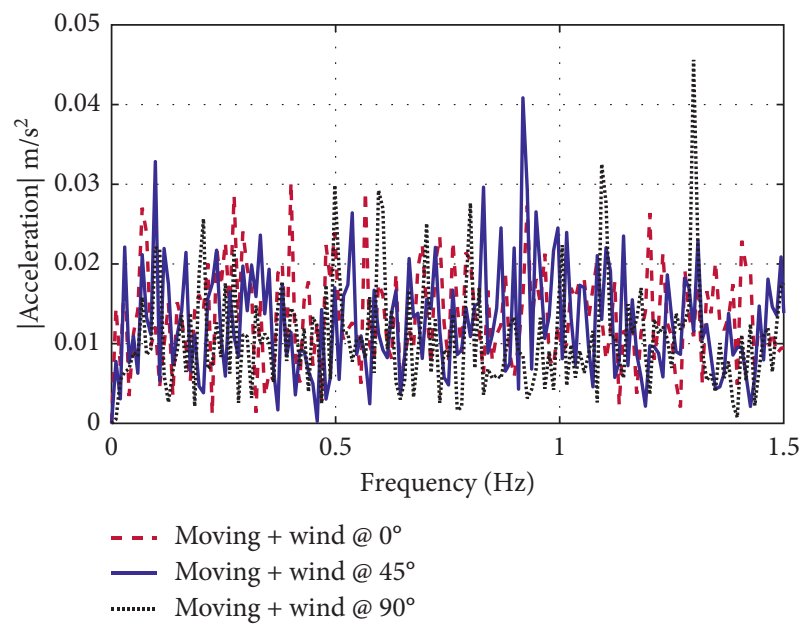

(b)

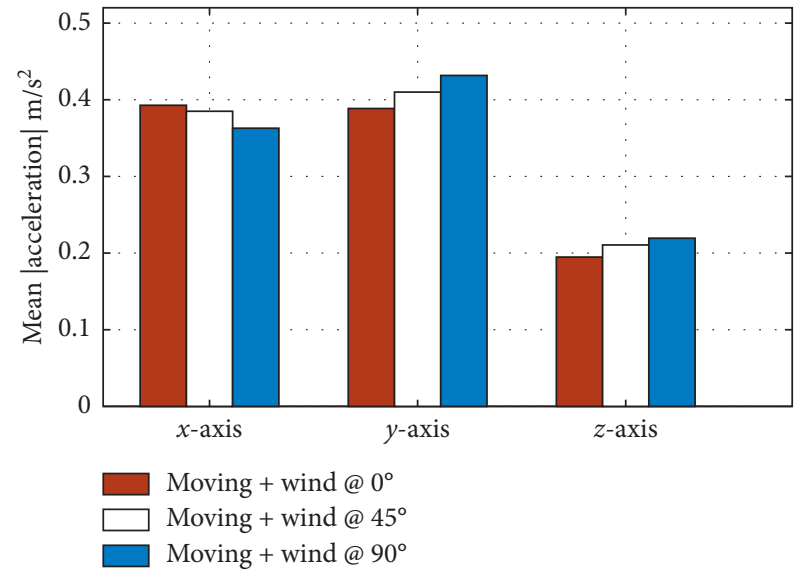

(c)

(d)

FiguRE 15: Experimental response of the moving robot under different wind attack angles. (a) $x$-axis; (b) $y$-axis; (c) $z$-axis; (d) summary.

the experimental setup of Figure 13. Due to the limitation of the power line cable, the robot is allowed to move forward along the line for six seconds, stops for 2 seconds, and then reverses back for another six seconds. The robot speed is controlled at $10 \mathrm{~m} / \mathrm{min}$ for the duration of 5 minutes for each test using the $\pm 24 \mathrm{~V}$ battery, as shown in Figure 14. This allows the robot-line dynamics to be adequately studied in real-time. The robot trunk is assumed to be the most vulnerable point to external disturbance and hence, selected as the vibration measurement point.

To investigate the robustness of the robot to external disturbance, the system is subjected to external wind of 


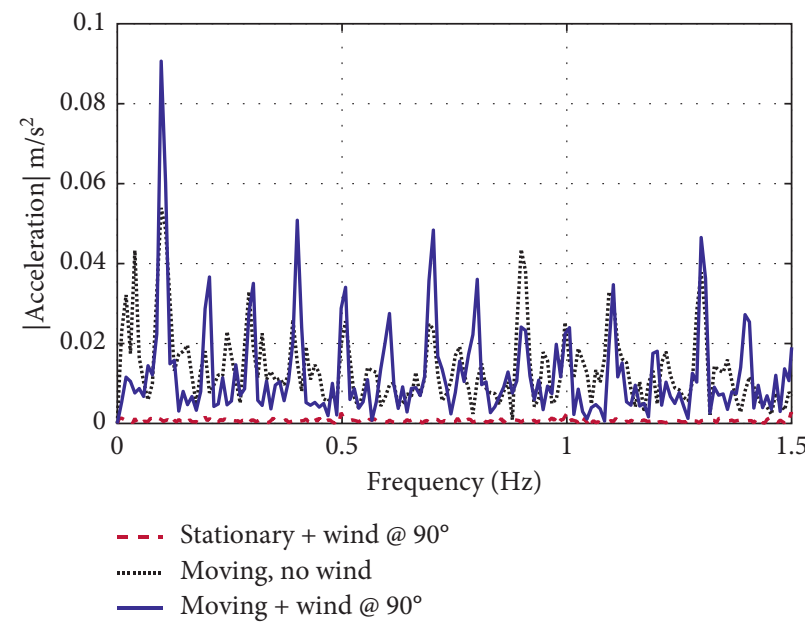

(a)

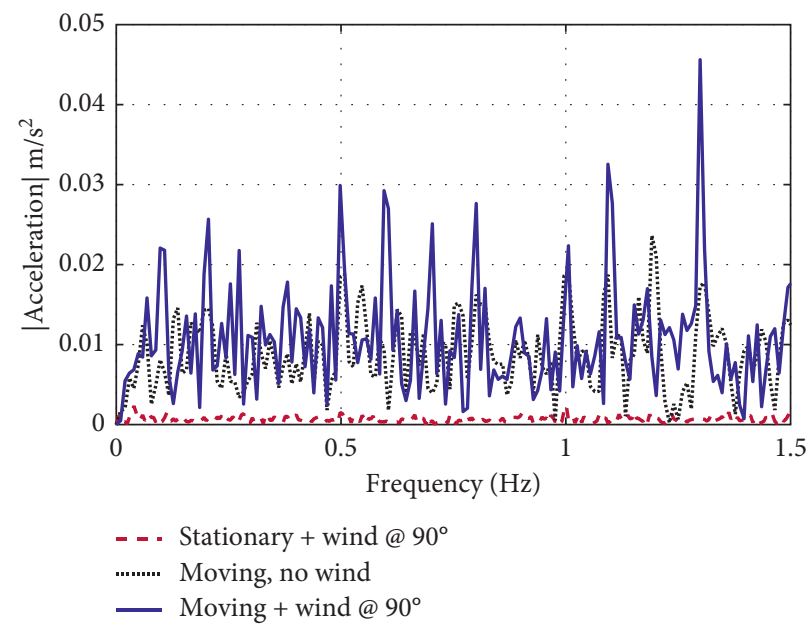

(c)

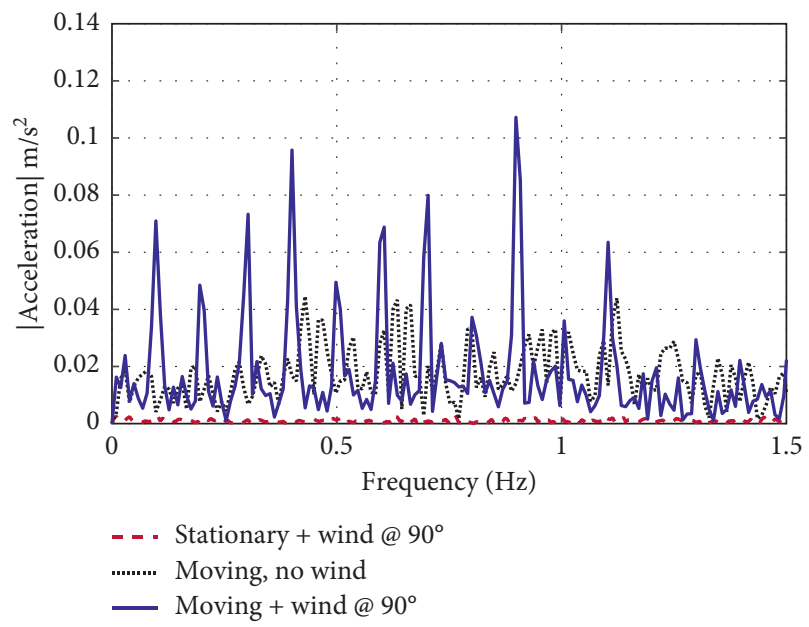

(b)

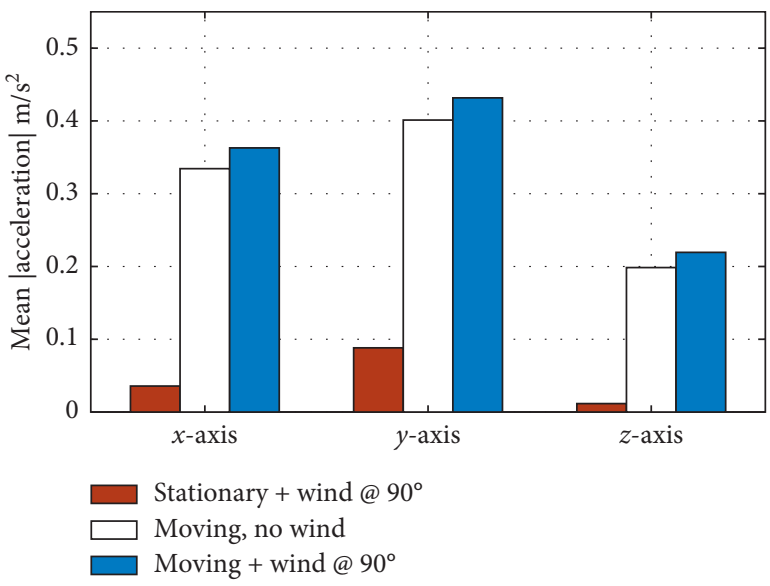

(d)

FIGURE 16: Experimental response of the robot under different conditions. (a) $x$-axis; (b) $y$-axis; (c) $z$-axis; (d) summary.

different magnitudes. In addition, to realize the exact effect of the wind on the system, the actual wind activities in China within the years 1960-2016 as documented in [57] are considered. Based on the report, Chinese capital, Beijing, is one of the windiest cities in China with an average wind speed of $2.4 \mathrm{~m} / \mathrm{s}$ to $4.2 \mathrm{~m} / \mathrm{s}$; thus, it is taken as the case study for our analysis.

Also, to fully analyze the aerodynamic behavior of the system, the vibratory responses for three different scenarios were studied, namely, vibration for wind-free environment, vibration due to external wind, and vibrations for different wind attack angles. Thus, the parameters adopted for the real-time analysis of the robot-line system are as follows: (1) the transmission line cable is $3 \mathrm{~m}$ long; (2) the robot is suspended on the line $1.8 \mathrm{~m}$ above the ground; (3) the total time for each experiment is 5 minutes; (4) the wind attack angles are set at $0^{\circ}, 45^{\circ}$, and $90^{\circ}$; and (5) the level of wind speed is set at $4.5 \mathrm{~m} / \mathrm{s}$ which covers the windiest ranges of wind in China.

Figures 15 and 16 show the response of the coupled system under different operating conditions. The results show that highest vibrations are recorded in the low-frequency ranges $(0-1.5 \mathrm{~Hz})$. To analyze the directional wind effects, the wind is subjected to the moving robot in three directions, i.e., $0^{\circ}, 45^{\circ}$, and $90^{\circ}$, as shown in Figure 15 .

The summary of the responses is presented in Figure 15(d) using the MAE of the vibrations of each axis. The results demonstrated that when the wind blows in $x$ axis, i.e., $0^{\circ}$, the vibration in $x$-axis is the highest $\left(0.39 \mathrm{~m} / \mathrm{s}^{2}\right)$. This shows that the $x$-axis vibration decreases by $3 \%$ and $8 \%$ when the wind acts, respectively, at $45^{\circ}$ and $90^{\circ}$ away from the $x$-axis. Similarly, the highest $y$-axis vibration of $0.43 \mathrm{~m} / \mathrm{s}^{2}$ is recorded when the wind acts at $90^{\circ}$, representing $11 \%$ increase in relation to vibration at $0^{\circ}$ in the same axis. However, $z$-axis with the highest vibration of $0.22 \mathrm{~m} / \mathrm{s}^{2}$ has the least vibrations in relation to that of $x$ and $y$ axes. This represents small vertical oscillations of the robot. It is obvious that the most unfavorable wind attack direction is $90^{\circ}$ since it affects the larger surface area of the robot-line system as earlier proved in equation (13).

Furthermore, the wind force is removed from the system and the robot is allowed to move in a controlled 


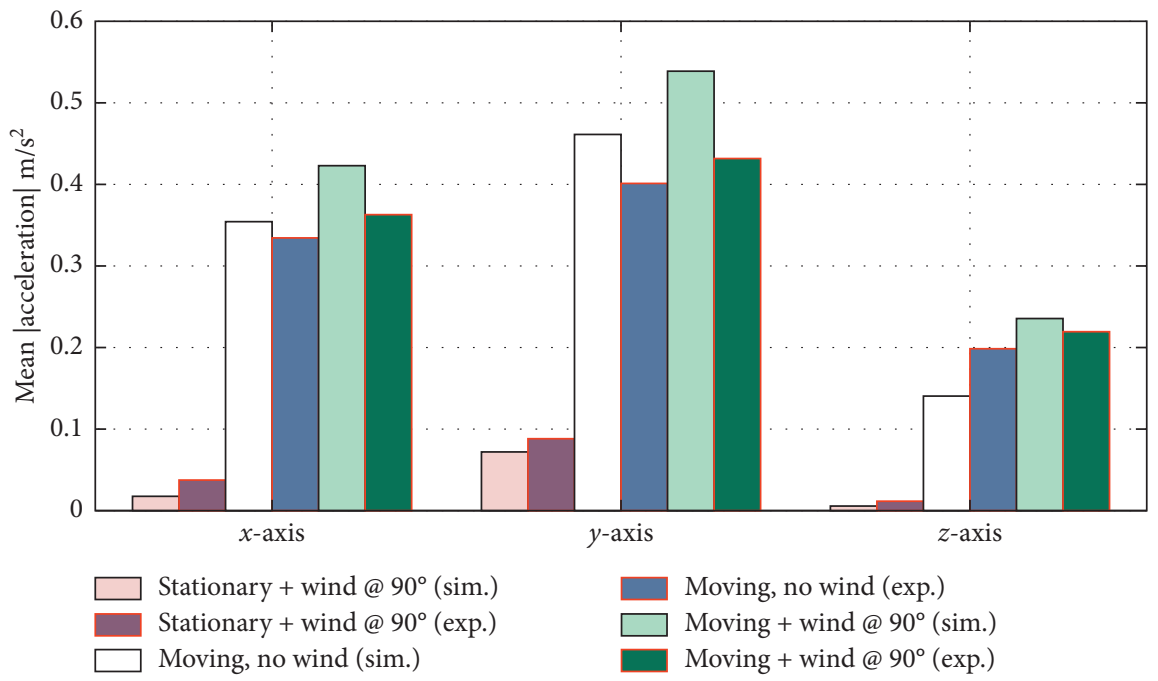

FIGURE 17: Summary of simulation and the experimental response of the robot under different conditions.

environment without wind $\left(v_{\mathrm{a}}=0 \mathrm{~m} / \mathrm{s}\right)$, and the corresponding vibration is recorded. Then, the robot is turned off (stop) while the most unfavorable wind attack at $90^{\circ}$ is exerted on the system, and the resulting response is also recorded. Finally, these two scenarios were compared with the maximum vibration obtained when the wind is applied to the moving robot at $90^{\circ}$, as shown in Figure 16 .

The summary of these responses of all the axes is illustrated in Figure 16(d). It can be seen that at stationary position, the robot has the least vibration while higher vibrations are recorded when subjecting the moving robot to external wind in all axes. In addition, $y$-axis recorded the highest vibration of $0.43 \mathrm{~m} / \mathrm{s}^{2}$, representing $7.5 \%$ increase in vibration as compared to the normal motion of the robot without wind disturbance $\left(0.40 \mathrm{~m} / \mathrm{s}^{2}\right)$ in the same axis.

Finally, the vibration of the simulations and the experimental results were compared in Figure 17. The response shows that the simulation results have higher vibrations as compared to the experiments. This is due to modelling uncertainties (assumptions) and the inherent electronic noises of the system. However, the pattern is similar, and both analyses confirmed that the robot is less vulnerable to wind attack even at the most unfavorable direction.

\section{Conclusions}

The main objective of this work is to improve the existing robots in terms of complexity, size, weight, and vulnerability to wind attack. Thus, this paper presents the development and performance analysis of a dual-arm power transmission line inspection robot under the influence of wind disturbance. The lightweight robot designed in Solidworks ${ }^{\circledR}$ was manufactured using the aluminum 6061 alloy. To investigate the effectiveness of the robot, the dynamic equations of the robot were derived, and a lab-scale power transmission line system was setup with an industrial fan as the wind source for the real-time wind effect analysis. The vibratory responses of the system under different operating conditions were obtained and studied. The conclusion of the whole paper can be summarized as follows:

(1) A power transmission line inspection robot is designed, manufactured, and experimentally tested on a lab-scale tower-line system.

(2) The dynamic equations for the joint torque analysis of the robot and the mechanism for wind disturbance on the robot-line system were presented.

(3) A wind speed of $4.5 \mathrm{~m} / \mathrm{s}$ which is equivalent to the windiest speed in China is considered as the case study for the wind effect analysis on the robot-line system.

(4) The effects of wind on the system in three directions $\left(0^{\circ}, 45^{\circ}\right.$, and $\left.90^{\circ}\right)$ were studied. The highest vibration is recorded when the wind acts perpendicular to the system. Thus, $90^{\circ}$ is the most unfavorable wind attack angle.

(5) The highest vibration is $8 \%$ more than the corresponding vibration without wind disturbance. This shows little influence of the wind on the deigned structure.

(6) The $0.5 \mathrm{~m}$ by $0.5 \mathrm{~m}$ robot only weighs $7.5 \mathrm{~kg}$ including the electronic components; thus, it is much lighter and portable as compared to the existing PTLIRs.

Finally, it can be concluded the robot has been successfully designed and can be applied for power transmission line inspection. Our future work will focus on control and installation of the imaging and sensing devices on the robot for real-time inspection of the power lines.

\section{Data Availability}

The data used to support the findings of this study are included within the article. 


\section{Conflicts of Interest}

The authors declare that there are no conflicts of interest regarding the publication of this paper.

\section{Acknowledgments}

This work was financed by the Key Project of Key Research and Development Program in Shaanxi, China (no. 2018ZDXM-GY-093).

\section{References}

[1] O. Menendez, F. A. Auat Cheein, M. Perez, and S. Kouro, "Robotics in power systems: enabling a more reliable and safe grid," IEEE Industrial Electronics Magazine, vol. 11, no. 2, pp. 22-34, 2017.

[2] K.-H. Seok and Y. S. Kim, "A state of the art of power transmission line maintenance robots," Journal of Electrical Engineering and Technology, vol. 11, no. 5, pp. 1412-1422, 2016.

[3] G. Yang, E. Li, C. Fan, W. Lei, and Z. Liang, "Adaptive fuzzy logic based inspection robot for high voltage power transmission line," in Proceedings of the 2010 IEEE International Conference on Information and Automation, pp. 613-618, Anchorage, AK, USA, May 2010.

[4] M. Karjalainen, E. Ahokas, J. Hyyppä et al., "Remote sensing methods for power line corridor surveys," ISPRS Journal of Photogrammetry and Remote Sensing, vol. 119, pp. 10-31, 2016.

[5] S. M. Luo and L. Tian, "Development of automatic linetracking inspection device for high voltage transmission lines based on ground control," in Proceedings of the 2011 IEEE International Conference on Computer Science and Automation Engineering, vol. 3, pp. 422-426, Shanghai, China, June 2011.

[6] M. F. A. Jalal, K. S. M. Sahari, A. Anuar, A. D. M. Arshad, and M. S. Idris, "Conceptual design for transmission line inspection robot," IOP Conference Series: Earth and Environmental Science, vol. 16, pp. 012094-012095, 2013.

[7] J. Sawada, K. Kusumoto, Y. Maikawa, T. Munakata, and Y. Ishikawa, "A mobile robot for inspection of power transmission lines," IEEE Transactions on Power Delivery, vol. 6, no. 1, pp. 309-315, 1991.

[8] K. Toussaint, N. Pouliot, and S. Montambault, "Transmission line maintenance robots capable of crossing obstacles: stateof-the-art review and challenges ahead," Journal of Field Robotics, vol. 26, no. 5, pp. 477-499, 2009.

[9] J. Katrasnik, F. Pernus, and B. Likar, "A survey of mobile robots for distribution power line inspection," IEEE Transactions on Power Delivery, vol. 25, no. 1, pp. 485-493, 2010.

[10] R. S. Gonçalves and J. C. M. Carvalho, "Review and latest trends in mobile robots used on power transmission lines," International Journal of Advanced Robotic Systems, vol. 10, no. 12, pp. 408-414, 2013.

[11] N. Pouliot and S. Montambault, "Field-oriented developments for LineScout technology and its deployment on large water crossing transmission lines," Journal of Field Robotics, vol. 29, no. 1, pp. 25-46, 2011.

[12] S. Montambault and N. Pouliot, "Hydro-Québec's power line robotics program: 15 years of development, implementation and partnerships," in Proceedings of the 2014 3rd International Conference on Applied Robotics for the Power Industry, Foz do Iguassu, Brazil, October 2014.
[13] P. Debenest, M. Guarnieri, K. Takita et al., "Expliner-robot for inspection of transmission lines," in Proceedings of the 2008 IEEE International Conference on Robotics and Automation, pp. 3978-3984, San Francisco, CA, USA, 2008.

[14] P. Debenest and M. Guarnieri, "Expliner-from prototype towards a practical robot for inspection of high-voltage lines," in Proceedings of the 2010 1st International Conference on Applied Robotics for the Power Industry, pp. 1-6, Montreal, Canada, October 2010.

[15] L. Wang, F. Liu, Z. Wang, S. Xu, J. Zhang, and S. Cheng, "Analysis and control of a biped line-walking robot for inspection of power transmission lines," in Proceedings of the 2011 IEEE International Conference on Robotics and Automation, pp. 5863-5868, Shanghai, China, May 2011.

[16] L. Wang, F. Liu, S. Xu, Z. Wang, S. Cheng, and J. Zhang, "Design, modeling and control of a biped line-walking robot," International Journal of Advanced Robotic Systems, vol. 7, pp. 39-47, 2010.

[17] D. Yang, Z. Feng, X. Ren, and N. Lu, "A novel power line inspection robot with dual-parallelogram architecture and its vibration suppression control," Advanced Robotics, vol. 28, no. 12, pp. 807-819, 2014.

[18] G. Tao and L. Fang, "A multi-unit serial inspection robot for power transmission lines," Industrial Robot: The International Journal of Robotics Research and Application, vol. 46, no. 2, pp. 223-234, 2019.

[19] E. J. Lima, M. H. S. Bomfim, and M. A. D. M. Mourão, "POLIBOT-POwer lines inspection RoBOT," Industrial Robot: An International Journal, vol. 45, no. 1, pp. 98-109, 2018.

[20] T. Guanghong and F. Lijin, "Optimization design of the multiunit serial inspection robot for power transmission line," in Proceedings of the 2016 4th International Conference on Applied Robotics for the Power Industry, pp. 1-6, Jinan, China, October 2016.

[21] C. M. Shruthi, A. P. Sudheer, and M. L. Joy, "Dual arm electrical transmission line robot: motion through straight and jumper cable," Automatika, vol. 60, no. 2, pp. 207-226, 2019.

[22] W. Wei, B. Yu-Cheng, W. Gong-Ping, L. Shui-Xia, and C. Qian, “The mechanism of a snake-like robot's clamping obstacle navigation on high voltage transmission lines," International Journal of Advanced Robotic Systems, vol. 10, no. 9, p. 330, 2013.

[23] B. Liu, M. Liu, X. Liu et al., "Design and realize a snake-like robot in complex environment," Journal of Robotics, vol. 2019, Article ID 1523493, 9 pages, 2019.

[24] B. Wang, L. Han, H. Zhang, Q. Wang, and B. Li, "A flying robotic system for power line corridor inspection," in Proceedings of the 2009 IEEE International Conference on Robotics and Biomimetics, pp. 2468-2473, Guilin, China, February 2009.

[25] S. Hrabar, T. Merz, and D. Frousheger, "Development of an autonomous helicopter for aerial powerline inspections," in Proceedings of the 2010 1st International Conference on Applied Robotics for the Power Industry, pp. 1-6, Montreal, Quebec, Canada, October 2010.

[26] B. Wang, X. Chen, Q. Wang, L. Liu, H. Zhang, and B. Li, "Power line inspection with a flying robot," in Proceedings of the 2010 1st International Conference on Applied Robotics for the Power Industry, pp. 1-6, Montreal, Quebec, Canada, October 2010.

[27] J. Zhang, L. Liu, B. Wang, X. Chen, Q. Wang, and T. Zheng, "High speed automatic power line detection and tracking for a 
UAV-based inspection," in Proceedings of the 2012 International Conference on Industrial Control and Electronics Engineering, pp. 266-269, Xi'an, China, August 2012.

[28] H. Li, B. Wang, L. Liu, G. Tian, T. Zheng, and J. Zhang, "The design and application of SmartCopter: an unmanned helicopter based robot for transmission line inspection," in Proceedings of the 2013 Chinese Automation Congress, pp. 697-702, Yangzhou, China, 2013.

[29] L. F. Luque-Vega, B. Castillo-Toledo, A. Loukianov, and L. E. Gonzalez-Jimenez, "Power line inspection via an unmanned aerial system based on the quadrotor helicopter," in Proceedings of the MELECON 2014-2014 17th IEEE Mediterranean Electrotechnical Conference, pp. 393-397, Beirut, Lebanon, April 2014.

[30] R. Qiu, X. Miao, S. Zhuang, H. Jiang, and J. Chen, “Design and implementation of an autonomous landing control system of unmanned aerial vehicle for power line inspection," in Proceedings of the 2017 Chinese Automation Congress (CAC), pp. 7427-7431, Jinan, China, October 2017.

[31] J. Bian, X. Hui, X. Zhao, and M. Tan, "A novel monocularbased navigation approach for UAV autonomous transmission-line inspection," in Proceedings of the 2018 IEEE/RSJ International Conference on Intelligent Robots and Systems (IROS), pp. 1-7, Madrid, Spain, October 2018.

[32] J. Bian, X. Hui, X. Zhao, and M. Tan, "A novel monocularbased navigation approach for UAV autonomous transmission-line inspection," in Proceedings of the 2018 IEEE/RSJ International Conference on Intelligent Robots and Systems, pp. 6207-6213, Madrid, Spain, October 2018.

[33] K. Máthé and L. Buşoniu, "Vision and control for UAVs: a survey of general methods and of inexpensive platforms for infrastructure inspection," Sensors, vol. 15, no. 7, pp. 1488714916, 2015.

[34] H. Shakhatreh, A. H. Sawalmeh, A. Al-Fuqaha et al., "Unmanned aerial vehicles (UAVs): a survey on civil applications and key research challenges," IEEE Access, vol. 7, pp. 48572-48634, 2019.

[35] Y. Zhang, X. Yuan, W. Li, and S. Chen, "Automatic power line inspection using UAV images," Remote Sensing, vol. 9, no. 8, p. 824, 2017.

[36] J. Katrašnik, F. Pernuš, and B. Likar, "A climbing-flying robot for power line inspection," in Climbing Walk, R. Behnam Miripour, Ed., pp. 95-110, University of Ljubljana, Slovenia, Balkans, 2010, https://www.intechopen.com/books/climbingand-walking-robots/a-climbing-flying-robot-for-power-lineinspection.

[37] W. Chang, G. Yang, J. Yu, Z. Liang, L. Cheng, and C. Zhou, "Development of a power line inspection robot with hybrid operation modes," in Proceedings of the 2017 IEEE/RSJ International Conference on Intelligent Robots and Systems, pp. 973-978, Madrid, Spain, September 2017.

[38] N. Pouliot, S. Lavoie, S. Montambault et al., "LineDrone technology: landing an unmanned aerial vehicle on a power line," in Proceedings of the 2018 IEEE International Conference on Robotics and Automation, pp. 6545-6552, San Francisco, CA, USA, 2018.

[39] E.-S. Abd-Elaal, J. E. Mills, and X. Ma, "A review of transmission line systems under downburst wind loads," Journal of Wind Engineering and Industrial Aerodynamics, vol. 179, pp. 503-513, 2018.

[40] Y. Xie, L. Huang, D. Wang, H. Ding, and X. Yin, "Modeling and analysis of progressive ice shedding along a transmission line during thermal de-icing," Mathematical Problems in Engineering, vol. 2019, Article ID 4851235, 12 pages, 2019.
[41] L. Zhao, X. Huang, Y. Zhang, Y. Tian, and Y. Zhao, "A vibration-based structural health monitoring system for transmission line towers," Electronics, vol. 8, no. 5, pp. 515611, 2019.

[42] C. Zhou, Y. Liu, and X. Rui, "Mechanism and characteristic of rain-induced vibration on high-voltage transmission line," Journal of Mechanical Science and Technology, vol. 26, no. 8, pp. 2505-2510, 2012.

[43] C. Zhou, Y. Liu, and Z. Ma, "Investigation on aerodynamic instability of high-voltage transmission lines under rain-wind condition," Journal of Mechanical Science and Technology, vol. 29, no. 1, pp. 131-139, 2015.

[44] C. Zhou and Y. Liu, "Modeling and mechanism of rain-wind induced vibration of bundled conductors," Shock and Vibration, vol. 2016, Article ID 1038150, 7 pages, 2016.

[45] X. Fu and H.-N. Li, "Dynamic analysis of transmission towerline system subjected to wind and rain loads," Journal of Wind Engineering and Industrial Aerodynamics, vol. 157, pp. 95$103,2016$.

[46] X. Fu, H.-N. Li, and G. Li, "Fragility analysis and estimation of collapse status for transmission tower subjected to wind and rain loads," Structural Safety, vol. 58, pp. 1-10, 2016.

[47] X. Fu and H.-N. Li, "Uncertainty analysis of the strength capacity and failure path for a transmission tower under a wind load," Journal of Wind Engineering and Industrial Aerodynamics, vol. 173, pp. 147-155, 2018.

[48] X. Li, W. Zhang, H. Niu, and Z. Y. Wu, "Probabilistic capacity assessment of single circuit transmission tower-line system subjected to strong winds," Engineering Structures, vol. 175, pp. 517-530, 2018.

[49] B. He, M. Zhao, W. Feng et al., "A method for analyzing stability of tower-line system under strong winds," Advances in Engineering Software, vol. 127, pp. 1-7, 2019.

[50] S. C. Yang and H. P. Hong, "Nonlinear inelastic responses of transmission tower-line system under downburst wind," Engineering Structures, vol. 123, pp. 490-500, 2016.

[51] Q. Xie, Y. Cai, and S. Xue, "Wind-induced vibration of UHV transmission tower line system: wind tunnel test on aeroelastic model," Journal of Wind Engineering and Industrial Aerodynamics, vol. 171, pp. 219-229, 2017.

[52] L. Tian, L. Guo, R. Ma, X. Gai, and W. Wang, "Full-scale tests and numerical simulations of failure mechanism of power transmission towers," International Journal of Structural Stability and Dynamics, vol. 18, no. 9, pp. 1-20, 2018.

[53] X. Fu, J. Wang, H.-N. Li, J.-X. Li, and L.-D. Yang, "Full-scale test and its numerical simulation of a transmission tower under extreme wind loads," Journal of Wind Engineering and Industrial Aerodynamics, vol. 190, pp. 119-133, 2019.

[54] F. Fan, G. Wu, M. Wang, Q. Cao, and S. Yang, "Multi-robot cyber physical system for sensing environmental variables of transmission line," Sensors, vol. 18, no. 9, pp. 3146-3229, 2018.

[55] A. Alhassan, Z. Mohamed, A. M. Abdullahi, A. A. Bature, A. Haruna, and N. M. Tahir, "Input shaping techniques for sway control of a rotary crane system," Jurnal Teknologi, vol. 80, no. 1, pp. 61-69, 2018.

[56] B. Wang, L. Song, and W. Chen, "Drag coefficient during strong typhoons," Advances in Meteorology, vol. 2013, Article ID 650971, 8 pages, 2013.

[57] C. Lin, K. Yang, J. Qin, and R. Fu, "Observed coherent trends of surface and upper-air wind speed over China since 1960," Journal of Climate, vol. 26, no. 9, pp. 2891-2903, 2013. 


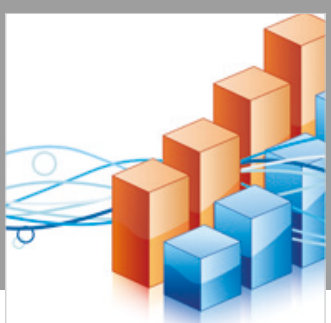

Advances in

Operations Research

\section{-n-m}
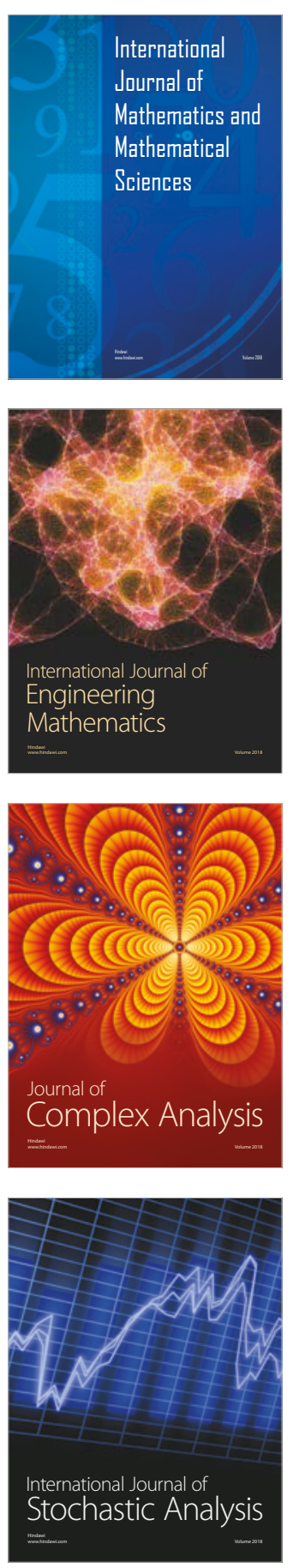
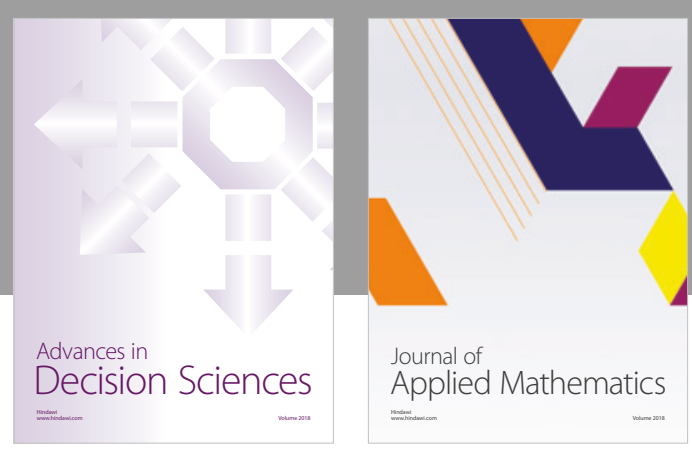

Journal of

Applied Mathematics
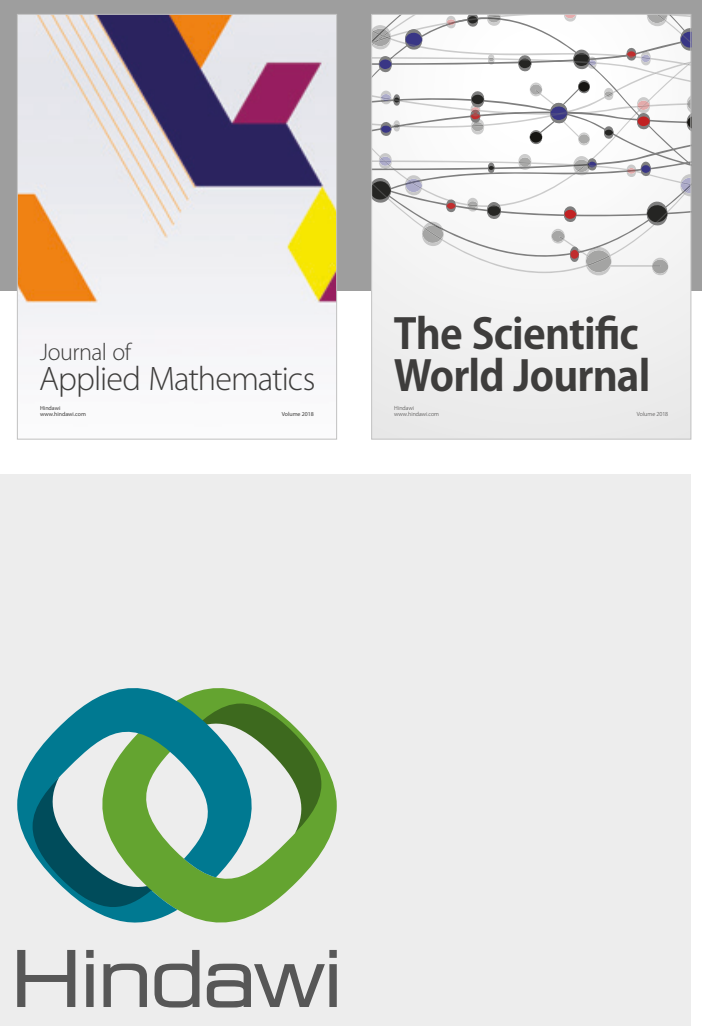

Submit your manuscripts at

www.hindawi.com

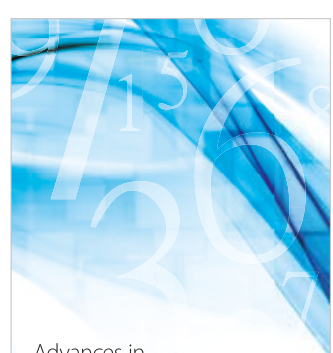

Advances in
Numerical Analysis
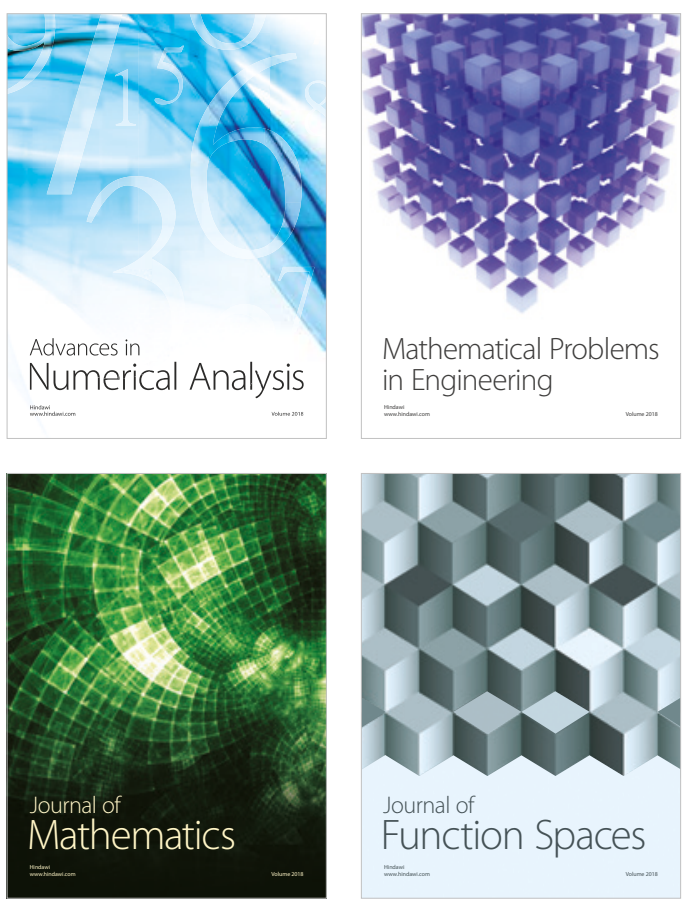

Mathematical Problems in Engineering

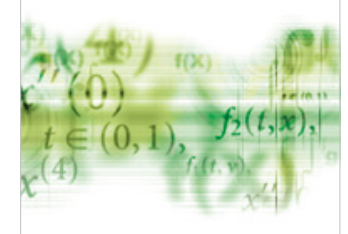

International Journal of

Differential Equations

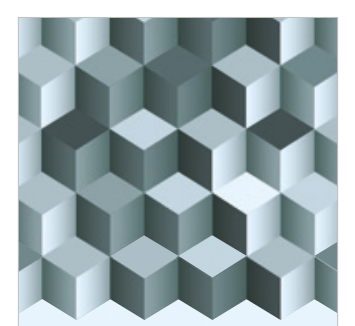

Journal of

Function Spaces

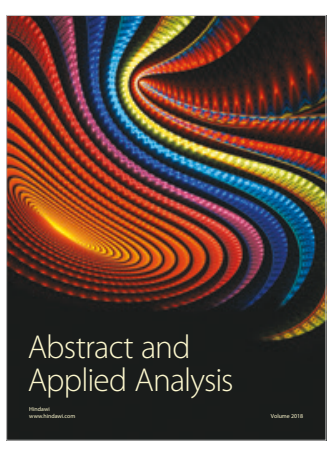

The Scientific

World Journal

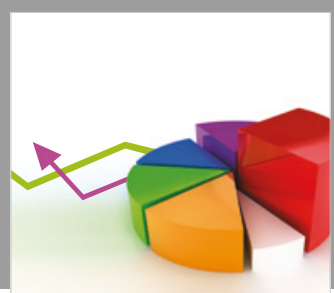

Journal of

Probability and Statistics
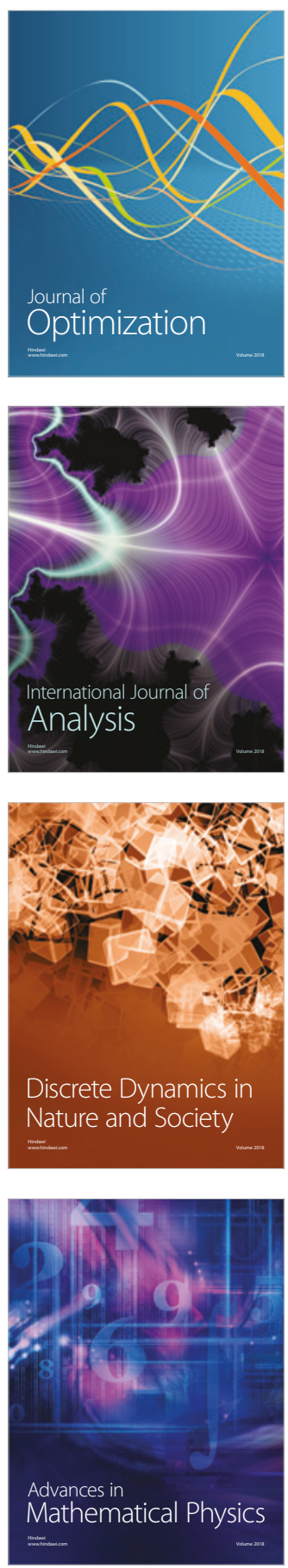